\title{
RNA around the clock - regulation at the RNA level in biological timing
}

\author{
Christine Nolte and Dorothee Staiger* \\ Molecular Cell Physiology, Faculty of Biology, Bielefeld University, Bielefeld, Germany
}

The circadian timing system in plants synchronizes their physiological functions with the environment. This is achieved by a global control of gene expression programs with a considerable part of the transcriptome undergoing 24-h oscillations in steady-state abundance. These circadian oscillations are driven by a set of core clock proteins that generate their own 24-h rhythm through periodic feedback on their own transcription. Additionally, post-transcriptional events are instrumental for oscillations of core clock genes and genes in clock output. Here we provide an update on molecular events at the RNA level that contribute to the 24-h rhythm of the core clock proteins and shape the circadian transcriptome. We focus on the circadian system of the model plant

\section{OPEN ACCESS}

Edited by:

Seth Jon Davis,

Max Planck Institute for Plant

Breeding Research, Germany

Reviewed by:

Ute Hoecker,

University of Cologne, Germany Michael Vincent Mickelbart,

Purdue University, USA

*Correspondence:

Dorothee Staiger,

Molecular Cell Physiology, Faculty of Biology, Bielefeld University,

Universitaetsstrasse 25,

Bielefeld D-33615, Germany dorothee.staiger@uni-bielefeld.de

Specialty section:

This article was submitted to Plant Physiology, a section of the journal Frontiers in Plant Science

Received: 09 February 2015 Accepted: 19 April 2015 Published: 05 May 2015

Citation:

Nolte $C$ and Staiger $D(2015)$ RNA around the clock - regulation at the RNA level in biological timing.

Front. Plant Sci. 6:311.

doi: 10.3389/fp/s.2015.00311
Arabidopsis thaliana but also discuss selected regulatory principles in other organisms.

Keywords: circadian oscillation, RNA-binding protein, post-transcriptional regulation

\section{Introduction}

\section{Regulation of the Flow of Genetic Information at the RNA Level}

The expression of eukaryotic genes is regulated at multiple levels. In the nucleus, transcription factors recruit RNA polymerase II to the gene's promoter. The access of transcriptional activators or repressors to the DNA in turn is licensed by chromatin remodeling factors. Once transcription has been initiated, pre-mRNAs enter a series of processing steps to mature mRNAs (Darnell, 2013). When the nascent pre-mRNA is ca. 20 nucleotides in length, its $5^{\prime}$ end receives the 7methylguanosine cap to protect the mRNA against degradation. Pre-mRNAs are spliced in the nucleus to remove introns, and differential usage of splice sites can give rise to multiple alternatively spliced transcript isoforms of one and the same pre-mRNA (Syed et al., 2012; Kornblihtt et al., 2013; Reddy et al., 2013). Polyadenylation signals determine the processing at the 3 ' end, i.e., the cleavage at a specific position before addition of the poly(A) tail that protects against degradation from the $3^{\prime}$ end (Proudfoot, 2011). Subsequently, the mature mRNA is exported from the nucleus for translation (Figure 1).

During this journey from the site of transcription in the nucleus to the cytoplasm the fate of the mRNAs is influenced by two main types of trans-acting regulators, RNA-binding proteins and non-coding RNAs. RNA-binding proteins, through dedicated domains, specifically recognize cis-active motifs in mRNAs to regulate their processing. The most frequent type of RNA-binding domain is the RNA recognition motif (RRM) of approximately 80 amino acids with a well conserved structure of four antiparallel $\beta$ strands packed against two $\alpha$ helices (Maris et al., 2005). Non-coding RNAs (ncRNAs) do not have a proteincoding potential. Numerous ncRNAs have emerged as important regulators of gene expression through the identification of cognate mRNA targets via base-pairing to sites with a variable degree of complementarity (Cech and Steitz, 2014). Non-coding RNAs are generally classified according to their size. Long non-coding RNAs (lncRNAs) vary in length between 


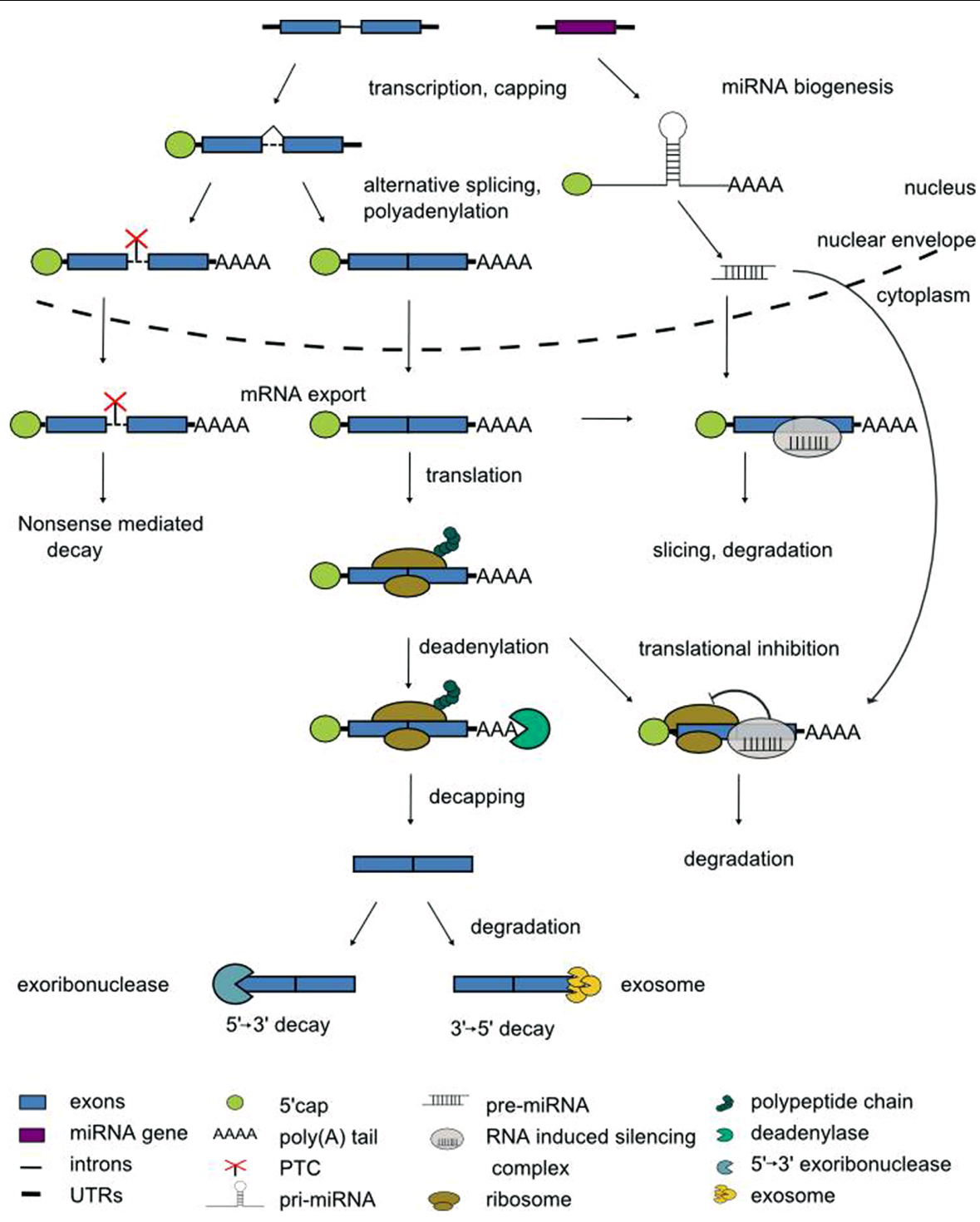

FIGURE 1 | Steps in pre-mRNA processing. See text for details.

ca. 200 nucleotides and dozens of kilobases (Kim and Sung, 2012). Small non-coding RNAs are between 20 and 25 nucleotides in length and are further classified according to their mode of biogenesis. Small interfering RNAs (siRNAs) are derived from double-stranded precursors whereas microRNAs (miRNAs) are derived from transcripts with partially double-stranded, hairpinlike structures (Figure 1; Rogers and Chen, 2013). Collectively, the pre-mRNA processing steps equip the cell with obvious checkpoints to rapidly modulate the transcriptome.

A prominent example of gene expression programs that continuously require fine tuning are periodic fluctuations in mRNA steady-state abundance across the day. Such daily rhythms in gene expression are controlled by an endogenous timing mechanism, the "circadian" clock. The circadian clock acts predominantly by directing promoter activity to defined time intervals of the day. However, off-switching of promoter activity is in many cases not sufficient to account for a steep decline from peak transcript levels to trough levels within a few hours to maintain correct phase, period and amplitude of transcript oscillations.

\section{The Circadian Timing System}

Plant physiology, biochemistry and behavior are orchestrated by the circadian system which serves to optimally align metabolic functions of the plant with the periodic changes in ambient light and dark phases (Barak et al., 2000; Eriksson and Millar, 2003; McClung, 2006; de Montaigu et al., 2010; Yerushalmi et al., 2011). Conceptually, the circadian timing system is divided into three functional units. The core clockwork is responsible for self-sustained 24-h rhythms of clock proteins. Input pathways ensure synchrony of the core clockwork with the day/night cycles through perception of periodic changes in light and temperature. 
Output pathways drive the expression of a large part of the circadian transcriptome with around a third of the protein-coding genes regulated by the circadian clock (Covington et al., 2008; Hazen et al., 2009). These gene expression rhythms translate into physiological and biochemical output rhythms.

The framework of the plant circadian timekeeping system has been established in Arabidopsis thaliana. Below we describe the components that are relevant for the topic we cover here. For a complete picture readers are referred to dedicated reviews (Yanovsky and Kay, 2001; Staiger, 2002; Harmer, 2009; McClung, 2011; Herrero and Davis, 2012; Nagel and Kay, 2012; Staiger et al., 2013; Hsu and Harmer, 2014). The core clockwork is made up by a series of autoregulatory circuits of clock proteins (Figure 2). The central loop consists of two Myb transcription factors LATE ELONGATED HYPOCOTYL (LHY) and CIRCADIAN CLOCK ASSOCIATED 1 (CCA1) peaking at dawn, and the pseudoresponse regulator TIMING OF CAB EXPRESSION1 (TOC1) peaking at dusk, that reciprocally repress their own expression (Alabadi et al., 2001; Gendron et al., 2012; Huang et al., 2012). This core loop is interconnected with a loop preferentially active in the morning and another loop preferentially active in the evening. Through the morning loop, LHY and CCA1 activate the expression of the PSEUDORESPONSE REGULATORS PRR9 and PRR7 which in turn repress CCA1 and LHY. PRR7 and PRR9 expression is switched off during the night through the evening complex (EC) consisting of the Myb-type transcription factor LUX ARRHYTHMO (LUX), EARLY FLOWERING 3 (EFL3) and ELF4 proteins (Dixon et al., 2011; Helfer et al., 2011; Herrero et al., 2012). As a result, CCA1 and $L H Y$ transcription resumes. In the evening loop, the $\mathrm{EC}$ and $\mathrm{TOC} 1$ reciprocally regulate their expression. The interconnection of these feedback loops is thought to contribute to robustness of the rhythmic expression patterns.

Modification of clock proteins, time-of-day dependent proteolysis and regulated nuclear uptake contribute to maintaining

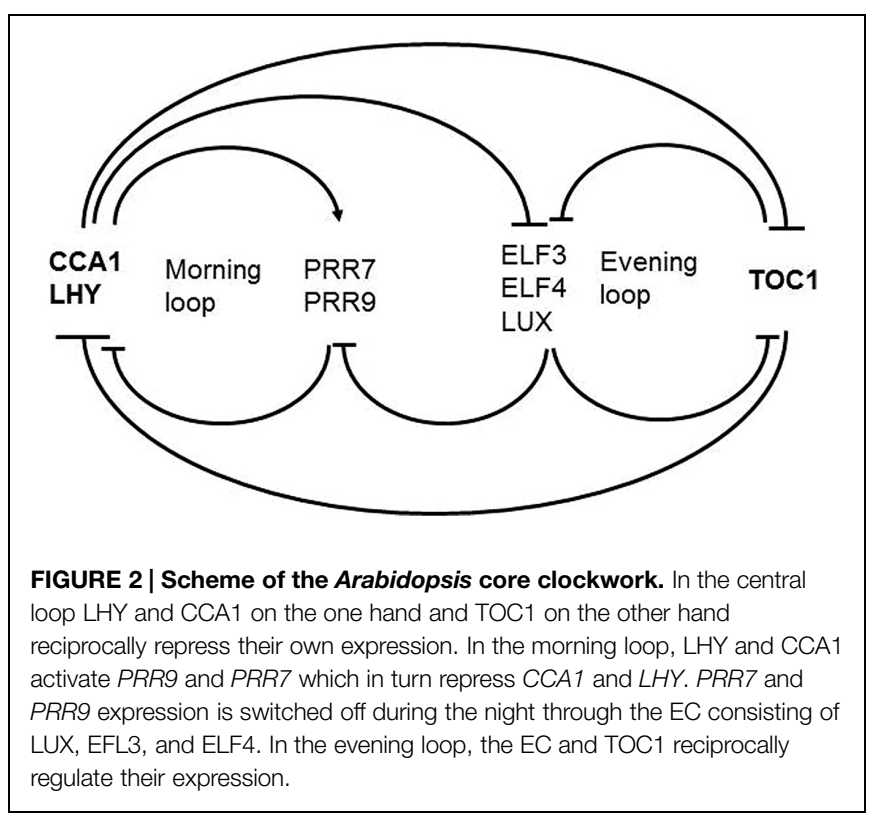

a period of 24 h (Mas et al., 2003; Fujiwara et al., 2008; Wang et al., 2010). These post-translational processes operating at the level of clock proteins are beyond the scope of this manuscript and have been reviewed elsewhere (Schöning and Staiger, 2005; Mehra et al., 2009; Seo and Mas, 2014).

Rhythms in eukaryotes generally arise in feedback loops of clock gene transcription/translation. The molecular players, however, are different in plants, arguing for an independent origin of plant and animal clocks (Roden and Carré, 2001). Below, we briefly touch upon the core components of the mammalian and fungal timing systems.

In mammals, the core clock loop comprises two transcription factors, CLOCK and BMAL1 that activate the Period (Per) 1, 2, and 3 and Cryptochrome (Cry) 1 and 2 genes (Young and Kay, 2001; Dibner et al., 2010; Partch et al., 2013). PER and CRY proteins undergo heterodimerization and are taken up into the nucleus to inhibit activation of their own genes by CLOCK and BMAL1. Upon proteoloytic degradation of CLOCK and BMAL1 a new cycle can then be initiated.

In Neurospora crassa, the transcription factors White collar 1 (WC-1) and WC-2 form the white collar complex (WCC), which drives the rhythmic expression of the frequency (frq) clock gene (Liu et al., 1999; Bell-Pedersen et al., 2005). FRQ interacts with frequency interacting RNA helicase (FRH). The resulting FRQ/FRH complex in turn inhibits WCC activity.

\section{Layers of Post-Transcriptional Control in the Circadian Timing System}

Transcription is considered the prime mechanism driving rhythmic gene expression both in the core clockwork and in clock output. However, mRNA steady-state abundance is determined by the rates of both transcription and degradation and theoretical considerations have led to the conclusion that transcriptional rhythms are manifest in high amplitude mRNA cycling only when the mRNA has a sufficiently short half-life (Wuarin et al., 1992; Lück et al., 2014).

Enhancer trapping using a promoter-less luciferase reporter in Arabidopsis unveiled that one third of the genome is under transcriptional control by the clock (Michael and McClung, 2003). However, the LHCB1*3 (LIGHT HARVESTING CHLOROPHYLL $B I N D I N G$ PROTEIN) promoter is clock-regulated but transcript levels are constitutive, suggesting that changes in mRNA stability obscure rhythmic transcription (Millar and Kay, 1991). CATALASE3 mRNA oscillations damp to a high level in constant darkness while CATALASE3 promoter-driven luciferase activity still oscillates with an evening peak (Zhong et al., 1997; Michael and McClung, 2002). On the contrary, NITRATE REDUCTASE mRNA oscillates despite a time-of-day independent transcription rate (Pilgrim et al., 1993).

In mammals, about $10 \%$ of the transcripts in the liver undergo circadian oscillations (Akhtar et al., 2002). A comprehensive RNA-seq analysis uncovered that rhythms of only $22 \%$ of them are driven by de novo transcription (Koike et al., 2012). Furthermore, a recent transcriptome analysis with 2 -h resolution around the clock found that $10 \%$ of the $N$. crassa transcriptome is reproducibly rhythmic at the mRNA level under normal growth conditions, and that the circadian clock may influence as much 
as $40 \%$ of the genome under other conditions (Hurley et al., 2014). A parallel high-throughput assay for timing of promoter activity using the luciferase reporter unveiled significant discordance between promoter activity and transcript oscillations. These discrepancies between clock-controlled transcription and oscillations in mRNA steady-state abundance pointed to additional levels of control impinging on clock-regulated transcripts and thus post-transcriptional regulation moved centre-stage in chronobiology.

Here, we discuss our current view on RNA-based regulation of gene expression in the Arabidopsis circadian timing system. Additionally, selected examples of RNA processing steps that have been shown to shape the daily pattern of transcripts in other model organisms including mammals, the fly Drosophila melanogaster and the bread mold $N$. crassa are presented for an integrated view. For a general survey of post-transcriptional regulation in these circadian clock systems readers are referred to comprehensive reviews (Crosthwaite, 2004; Harms et al., 2004; Keene, 2007; Kojima et al., 2011; Staiger and Green, 2011; Staiger and Köster, 2011; Zhang et al., 2011; Wang et al., 2013; Kojima and Green, 2014).

\section{Alternative Splicing in the Circadian System}

In plants, our understanding of post-transcriptional regulation of circadian timekeeping is most advanced for alternative splicing. We begin by briefly describing key points of the mechanism, the players and the outcome of alternative splicing before turning to its relevance for circadian timekeeping in Arabidopsis and conclude by selected examples of alternative splicing in other model organisms of chronobiology.

\section{Regulation of Alternative Splicing}

During pre-mRNA splicing, introns are excised and the flanking exons are joined. However, not every splice site is used each time a pre-mRNA is processed. Rather, through the variable use of splice sites exonic sequences can be lost or intronic sequences can remain in the mRNA, designated as alternative splicing. During exon skipping, exons are removed together with their flanking introns (Figure 3A). The use of alternative $5^{\prime}$ splice sites or alternative $3^{\prime}$ splice sites causes variable portions of introns to be removed and variable portions of exons to remain in the mRNA (Figures 3B,C). During intron retention, introns can stay in the pre-mRNA (Figure 3D). Due to this variation in splicing patterns the corresponding proteins can be composed of distinct domains and thus have different functions (Nilsen and Graveley, 2010; Carvalho et al., 2012; Syed et al., 2012; Reddy et al., 2013). This tremendously increases the coding capacity of the genome. At the RNA level, alternative splice isoforms can have a different inventory of cis-regulatory sequence motifs and thus be differentially recognized by RNAbinding proteins or miRNAs. Alternative splice isoforms can also be identified as being "aberrant" and targeted for degradation. For example, if intronic sequences are retained, the open reading frame (ORF) may terminate at a premature termination codon

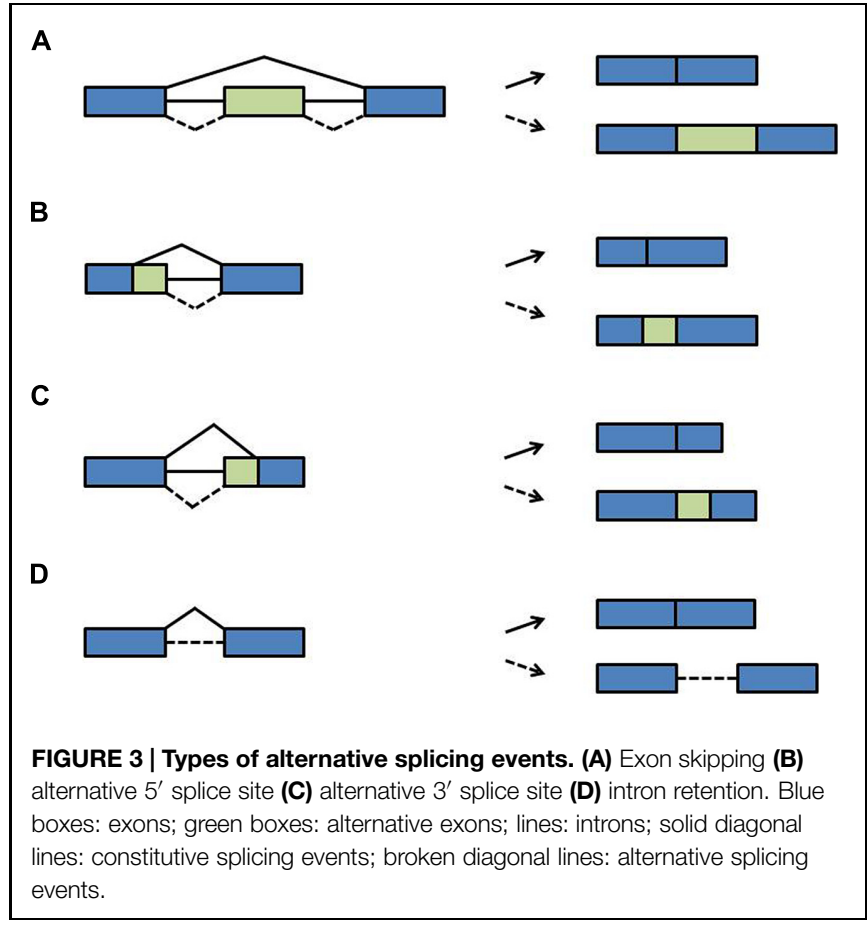

(PTC). Such PTCs are recognized by the nonsense-mediated decay (NMD) pathway, a surveillance mechanism that eliminates aberrant transcripts (Arciga-Reyes et al., 2006; Isken and Maquat, 2008). Through linkage with NMD, alternative splicing can lead to quantitative changes in overall transcript levels (McGlincy and Smith, 2008; Nicholson and Mühlemann, 2010). Of note is that the NMD pathway has recently been shown to contribute to innate immunity in plant-pathogen-interaction and thus may have more widespread physiological roles (Gloggnitzer et al., 2014).

Pre-mRNA splicing is executed by a high molecular weight machine in the cell, the spliceosome. The main components of the spliceosome are five ribonucleoprotein (RNP) complexes with specific RNAs designated the U-rich small nuclear RNAs (U snRNAs). U1, U2, U4, and U5 assemble with the Sm proteins B/B', D1, D2, D3, E, F, and G to form U snRNPs. The U6 snRNP contains the related LSM2 (Like-Sm2) to LSM8 proteins (Tharun, 2009; Golisz et al., 2013).

The decision whether a particular splice site is used is influenced by additional RNA-binding proteins that interact with distinct motifs in the pre-mRNAs to favor or inhibit the recruitment of the spliceosome to neighboring alternative splice sites (Reddy et al., 2012, 2013; Kornblihtt et al., 2013). These regulators are mainly serine/arginine-rich (SR) proteins or heterogeneous nuclear ribonucleoparticle proteins (hnRNPs). The SR proteins contain one or two RRMs as well as a domain with a high proportion of arginine/serine repeats (Reddy, 2004; Barta et al., 2010). The hnRNPs are a diverse class of RNA-binding proteins with one or multiple RRMs or RNA binding domains of the $\mathrm{K}$ homology $(\mathrm{KH})$ motif type, originally found in human hnRNP K (Wachter et al., 2012). Numerous components involved in pre-mRNA splicing have 
been identified in $A$. thaliana, based on homology to yeast and mammalian sequences (Koncz et al., 2012; Reddy et al., 2013).

\section{Alternative Splicing in the Core Clockwork}

Whole transcriptome sequencing has uncovered a prominent role of alternative pre-mRNA splicing in the plant circadian system (Sanchez et al., 2011; Syed et al., 2012; Henriques and Mas, 2013; Staiger and Brown, 2013; Cui et al., 2014). For the core clock gene CCA1 an alternative splice isoform was found to increase upon exposure of the plants to high light and decrease upon exposure to cold (Filichkin et al., 2010). This splice isoform retains intron 4, the long intron following the Myb-domain encoding exons, and thus can give rise to a truncated protein due to a PTC (Figure 4A). The splicing factor SR45 is able to bind to the intron in vitro, suggesting that it may function in alternative splicing of intron 4 (Filichkin et al., 2015).

A targeted search for alternative splice isoforms of the Arabidopsis clock genes using a high resolution Reverse transcription-PCR based alternative splicing panel uncovered that alternative splicing is widespread in the core clock (James et al., 2012). For $L H Y$, an alternative splice isoform containing an alternative exon was found due to alternative splicing at the long intron 5 (that corresponds to intron 4 in the related CCA1 transcript; Figure 4B). This splice isoform accumulates when plants are shifted to low temperature. Because it contains a PTC and is a substrate for the NMD pathway the production of full length LHY protein is precluded and thus LHY protein levels decline at low temperature (James et al., 2012). In contrast, CCA1 intron 4 retention decreases at low temperature, and the CCA1 transcript transiently shows a higher and broader peak upon shift to low temperature. These data suggest that alternative splicing may adjust the core oscillator to low temperatures, and the differential behavior of CCA1 and LHY in this response may contribute to the overlapping but not redundant action of these two proteins in the clock mechanism.

Subsequently, autoregulation of CCA1 has been proposed to underlie this low temperature response. The CCA1 alternative splice isoform retaining intron 4 including a PTC accumulates at low temperature, as described above, and can produce a polypeptide comprising only the N-terminal MYB domain (Figure 4A). This transcript has been predicted to produce a protein that consists of the C-terminal dimerization domain without the DNA-binding MYB domain, designated CCA1 $\beta$ (Figure 4A; Seo

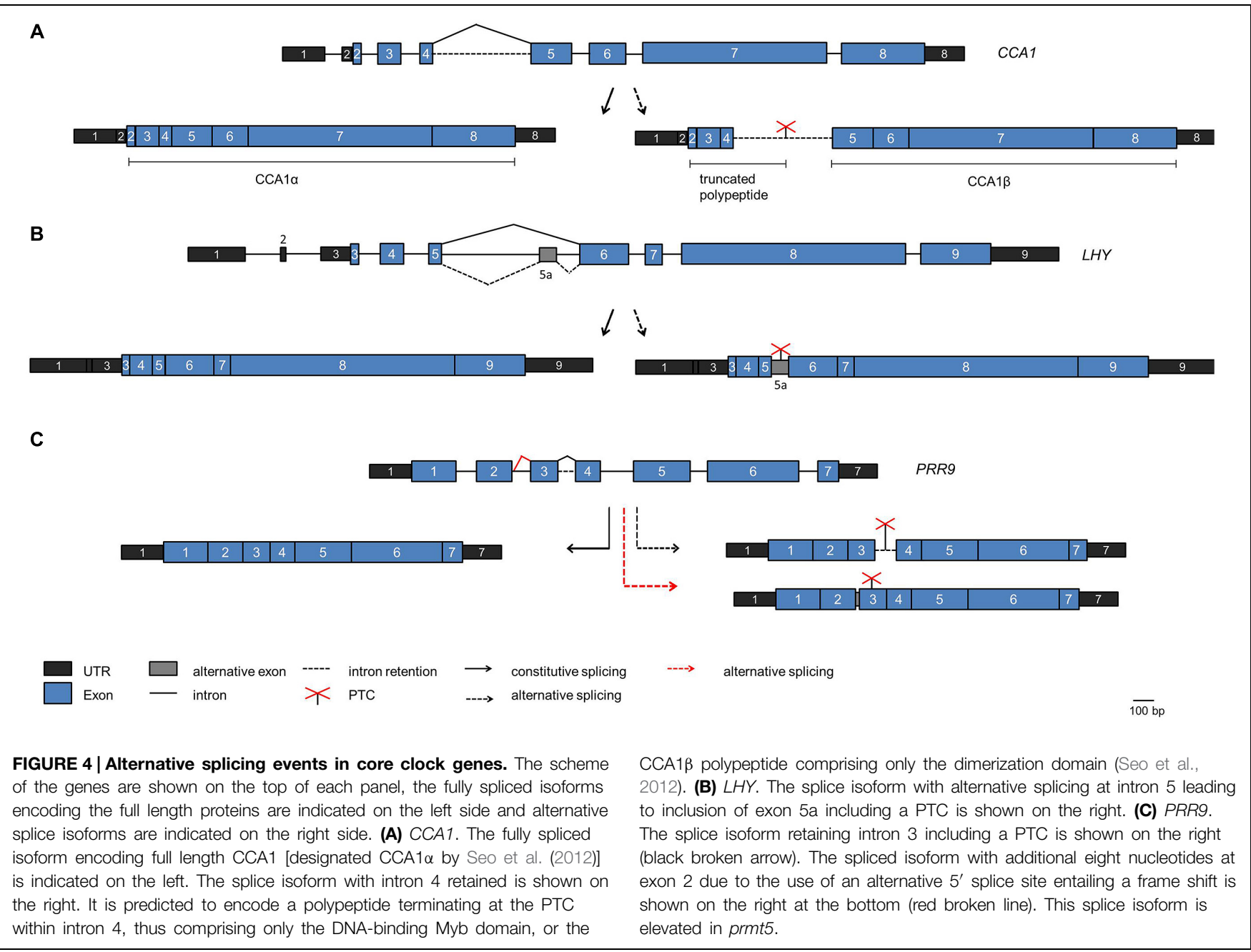


et al., 2012). Upon targeted over-expression in transgenic plants CCA $1 \beta$ interferes with complex formation of the full length CCA $1 \alpha$ protein both with itself and with LHY and thus with their function as transcriptional repressors in the core clock. Indeed, over-expression of CCA $1 \beta$ from a constitutive promoter leads to a short period phenotype, as observed in ccal lhy mutants, consistent with CCA1 $\beta$ acting as a dominant negative inhibitor. It remains to be demonstrated whether such a reinitiation of translation downstream of an ORF occurs in planta to produce the CCA1 $\beta$ protein.

Similar to CCA1 and LHY, PRR7, and PRR9 are thought to act partially redundantly in the clock. For $P R R 7$ non-functional alternative splice isoforms transiently accumulate to substantial levels upon exposure to low temperatures and thus would lead to reduced PRR7 levels. In contrast, PRR9 transiently increases at low temperatures, but the PRR9 alternative splicing events that lead to non-functional transcripts due to intron 3 retention or inclusion of eight nucleotides at the end of exon 2 are not influenced by temperature (Figure 4C; James et al., 2012). This points to differences in the regulation of this pair of clock proteins. TOC1/PRR1 and PRR5 are also alternatively spliced to PTC-containing isoforms at low temperatures.

Alternative splicing of clock genes has also been observed upon exposure to high temperatures, e.g., for the $L U X, L O V$ KELCH PROTEIN 2 and TIME FOR COFFEE (TIC) transcripts but the physiological consequences for clock function have not been addressed (Filichkin and Mockler, 2012).

For $P R R 7$ and $L H Y$ rapid changes in alternative splicing patterns in response to red light activation of the phytochrome photoreceptor have been uncovered (Shikata et al., 2014). Given the role of phytochrome in mediating light input (Fankhauser and Staiger, 2002; Millar, 2004), it is conceivable that such changes in alternative splicing may impact light entrainment of the clock.

\section{Alternative Splicing in Clock Output}

Currently it is estimated that alternative splicing affects more than $60 \%$ of all intron-containing genes in Arabidopsis (Marquez et al., 2012). The functional relevance of most of the alternative splice isoforms remains to be demonstrated (Carvalho et al.,
2012). A differential function was found for two RIBULOSE1,5-BISPHOSPHATE CARBOXYLASE ACTIVASE (RCA) protein variants encoded by splice isoforms. The $R C A$ transcript undergoes circadian oscillations in steady-state abundance as well as circadianly regulated alternative splicing (Sanchez et al., 2010). A short alternative splice isoform encodes a protein that acts independent of light, and a long alternative splice isoform encodes a protein isoform regulated by light (Zhang et al., 2002). Alternative splicing of the mRNA isoform that encodes the light-regulated protein increases during the day (Sanchez et al., 2010).

The use of whole-genome tiling arrays for transcript profiling around the clock unveiled circadian rhythms in the steadystate level of numerous introns (Hazen et al., 2009). In cases where these retained introns are embedded in rhythmically expressed genes and oscillate in phase with their surrounding exons, the retained introns should lead to truncated protein variants.

\section{A Circadian Feedback Loop based on Alternative Splicing and NMD}

AtGRP7 (A. thaliana glycine-rich RNA binding protein 7) and AtGRP8 are clock-regulated RNA binding proteins which peak at the end of the day. Both AtGRP7 and AtGRP8 negatively autoregulate through alternative splicing (Figure 5). A transcript isoform retaining part of the intron including a PTC is generated that rapidly decays via NMD (Staiger and Heintzen, 1999; Schöning et al., 2008). Upon mutation of a conserved arginine residue in the RRM the in vitro and in vivo RNA binding activities as well as the negative autoregulation of AtGRP7 are lost (Schöning et al., 2007; Köster et al., 2014a; Leder et al., 2014). AtGRP7 and AtGRP8 thus represent two clock-regulated feedback circuits that additionally cross-regulate via alternative splicing and NMD. These were the first examples of feedback loops based on posttranscriptional regulation in the circadian system. AtGRP7 and AtGRP8 in turn regulate steady-state abundance or alternative splicing of several transcripts which undergo circadian oscillations themselves, suggesting that the AtGRP7/AtGRP8 feedback loops pass timing information from the core oscillator to clock output (Rudolf et al., 2004; Streitner et al., 2010, 2012; Schmal et al., 2013).

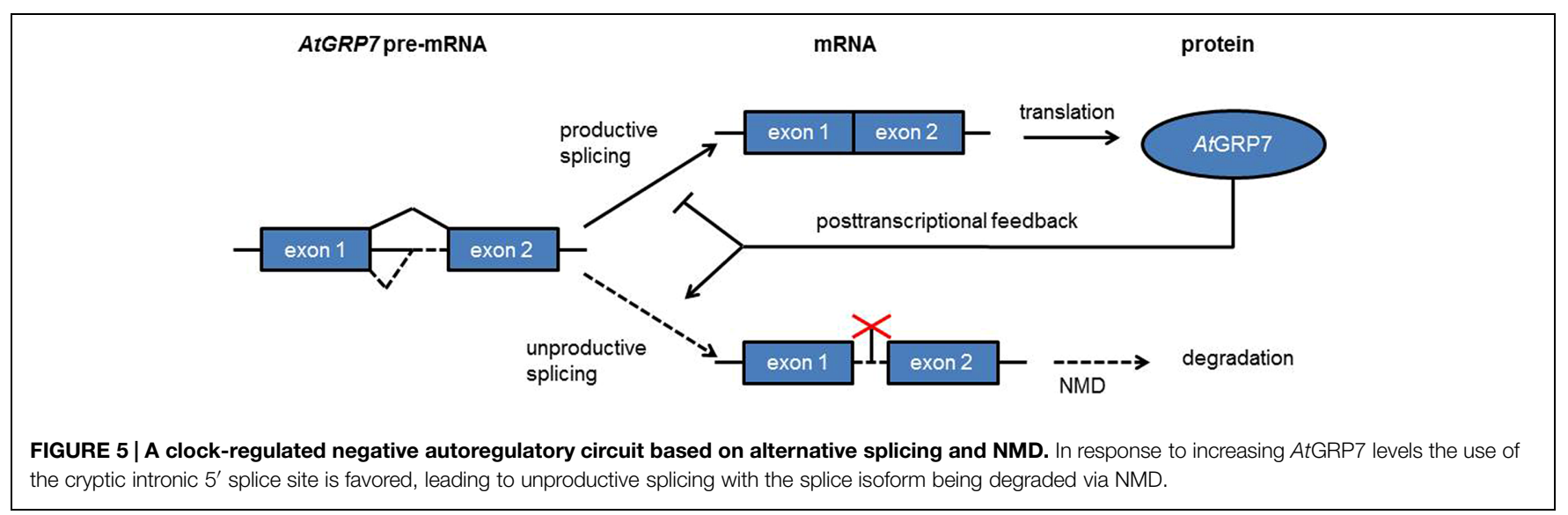


Apart from circadian rhythms, AtGRP7 has been shown to be involved in the low temperature response, response to oxidative stress, flowering time control and pathogen defense (Kim et al., 2007b, 2008; Schmidt et al., 2010; Nicaise et al., 2013; Hackmann et al., 2014; Löhr et al., 2014). This suggests that it may exert widespread post-transcriptional control in the cell and integrate responses to external stimuli with endogenous timing cues.

\section{A Defective Clock in Mutants of Candidate Splicing Components}

A long period circadian phenotype has been observed in mutants deficient in PROTEIN METHYLTRANSFERASE 5 (PRMT5; Sanchez et al., 2010, 2011). PRMT5 is a type II protein arginine methyltransferase that symmetrically dimethylates arginine side chains, i.e., deposits a methyl group on either one of the two terminal guanidino nitrogens. PRMT5 acts upon a broad spectrum of substrates that can be detected by antibodies against symmetrically dimethylated arginine in wild type plants, but not in the prmt5 mutant. Among those are numerous proteins involved in RNA processing including AtSmD1, AtSmD3, and LSM4 (Deng et al., 2010). In Arabidopsis, a complex of LSM2 to LSM8 complex is part of U snRNPs and thus functions in pre-mRNA splicing (Perea-Resa et al., 2012). In prmt5, PRR9 levels are greatly elevated compared to wild type plants. As PRR9 over-expression leads to a short period of the clock, altered PRR9 steady-state abundance seemed unlikely to cause the prmt5 long period phenotype (Matsushika et al., 2002). However, the PRR9 transcript was aberrantly spliced in prmt5. An alternative splice isoform with a PTC due to the use of an alternative $5^{\prime}$ splice site at intron 2 accumulate at the expense of the functional isoform (Figure 4B). This suggests that the long period in prmt5 can be partly attributed to aberrant PRR9 splicing. When the prmt5 mutant was analyzed on tiling arrays, a global impact of PRMT5 on alternative splicing was found. The use of the high resolution alternative splicing panel then unveiled that PRMT5 function is required in particular to activate weak $5^{\prime}$ splice sites (Sanchez et al., 2010).

Subsequently, mutants defective in the PRMT5 substrate LSM4 were also linked to circadian regulation. The lsm 4 mutant shows long period oscillations of gene expression as well as aberrant splicing of several clock genes (Perez-Santángelo et al., 2014). The $l s m 5$ mutant, previously identified because of its hypersensitivity to abscisic acid and thus named sad1 (supersensitive to abscisic acid 1) also led to long period leaf movement rhythms (Perez-Santángelo et al., 2014). The expression of several clock genes is altered in lsm5. Furthermore, there is an increase in TOC1 intron 4 retention, similar to wild-type plants exposed to low temperature conditions, and intron 2 is retained in CCA 1 . A genome-wide analysis of both mutants uncovered a more widespread role of LSM4 in the control of alternative splicing. Notably, the LSM5 transcript undergoes circadian oscillations itself. Such a clock regulation of splicing regulators like LSM5 or AtGRP7 may serve as a means to coordinate time-of-day dependent changes in splicing of a cohort of target genes (Staiger, 2001; Perez-Santángelo et al., 2013).
Mutations in two other splicing factors, Ski-interacting protein (SKIP) and SPLICEOSOMAL TIMEKEEPER LOCUS 1 (STIPL1), led also to a long period of the clock (Jones et al., 2012; Wang et al., 2012). The yeast and human SKIP counterparts have a demonstrated role as splicing factors (Gahura et al., 2009). AtSKIP associates with the splicing factor SR45 and in the skip-1 mutant, alternative splicing of PRR7 and PRR9 is defective, contributing to the long period phenotype (Wang et al., 2012). STIPL1 encodes a homolog of TUFTELININTERACTING PROTEIN 11 (TFIP11) in humans and Ntr1p in yeast involved in spliceosome disassembly (Tannukit et al., 2009; Jones et al., 2012). The altered expression of CCA1, LHY, PRR9, GI, and TOC1 caused by the aberrant splicing is likely to contribute to the circadian defects in the stipll mutant. The mechanisms of how the Arabidopsis proteins impact splicing of their targets remain to be described.

In mice, a very interesting rhythmic and light-induced alternative splicing event was described for the splicing factor U2AF26, a homolog of the small U2 auxiliary factor (U2AF) subunit U2AF35 involved in recognition of the $3^{\prime}$ splice site (Preußner et al., 2014). Through this alternative splicing events, translation of U2AF26 extends into the $3^{\prime}$ untranslated region $\left(3^{\prime}\right.$ UTR), generating a C-terminal extension of the ORF. This additional domain shows homology to the Drosophila clock protein Timeless, an interaction partner of Period. U2AF26deficient mice show nearly arrhythmic Period1 protein levels and aberrant mRNA cycling in peripheral clocks. Moreover, lack in U2AF26 leads to increased phase advance in response to alterations in the environmental light-dark cycles. These data suggest that light induced U2AF26 alternative splicing serves to limit Period1 induction in response to changes in ambient light and thus is involved in entrainment (Preußner et al., 2014).

\section{RNA Stability}

Eukaryotic mRNAs vary widely in their stabilities and mRNA turnover is exquisitely regulated (Houseley and Tollervey, 2009). The first step in mRNA degradation is the removal of the poly(A) tail, followed by exoribonuclease digestion from the $5^{\prime}$ end after removal of the cap structure or digestion from the $3^{\prime}$ end by the exosome, a multi-subunit machinery for RNA degradation in eukaryotes.

It has long been predicted that changes in mRNA halflife across the circadian cycle contribute to circadian transcript oscillations (So and Rosbash, 1997). In Arabidopsis, a suite of clock-controlled transcripts were identified in an approach to globally identify short-lived transcripts using DNA microarrays (Gutierrez et al., 2002). For two of them, CCR-LIKE (CCL) and SENESCENCE ASSOCIATED GENE 1, mRNA stability changes across the day. The changes in CCL mRNA stability continue under free-running conditions, indicating that they are controlled by the circadian clock (Lidder et al., 2005). Furthermore, degradation of these mRNAs is mediated by the downstream (DST) element first identified in the $3^{\prime}$ UTR of the auxin inducible 
SMALL AUXIN-UP RNAs and shown to destabilize mRNA (Newman et al., 1993). Of note, disruption of the DST-mediated RNA decay pathway leads to circadian defects (Lidder et al., 2005). Components of the DST pathway have not yet been reported.

For the core clock gene CCA1, a dependence of transcript stability on light quality has been found (Yakir et al., 2007). The CCA 1 mRNA is relatively stable in the dark but has a short halflife in the light. The light-dependent CCA1 mRNA degradation in combination with light-regulated $C C A 1$ transcription has been implicated in entrainment of the clock. Again, little is known about mechanisms such as, for example, RNA-binding proteins that regulate the access of nucleases, e.g., through steric hindrance or conformational changes in the mRNA depending on the light quality.

In mammals, changes in RNA stability contribute to oscillations of the core clock genes Cry $1, \operatorname{Per} 1, \operatorname{Per} 2$, and Per3, with a higher stability during the upswing and a lower stability during the downswing. Several cellular RNA-binding proteins including hnRNP D and hnRNP I, also known as the polypyrimidine tract binding protein PTB, have been shown to bind to the $3^{\prime}$ UTRs of clock transcripts in a circadian phase dependent manner, entailing their degradation (Kwak et al., 2006; Woo et al., 2009, 2010; Lee et al., 2014; Kim et al., 2015).

In $N$. crassa, the exosome is involved in regulation of several rhythmic transcripts (Guo et al., 2009). For example, downregulation of the Neurospora ortholog of RRP44, the $3^{\prime} \rightarrow 5^{\prime}$ exonuclease subunit of the exosome, leads to enhanced frq mRNA stability, higher frq levels and a longer period of frq mRNA oscillations. Because FRH interacts with the RRP44 ortholog, FRQ, FRH and the exosome are part of a post-transcriptional negative feedback loop interlocked with the clock transcriptional feedback loop that regulates WCC activity. The rrp44 transcript itself is clock-controlled suggesting that time-of-day-dependent exosome activity may play a wider role in circadian regulation.

In the green algae Chlamydomonas reinhardtii knockdown of XRN1, a $5^{\prime} \rightarrow 3^{\prime}$ exoribonuclease leads to low amplitude and rapid dampening of the bioluminescence rhythm (Matsuo et al., 2008). XRN1 has been shown to interact with the C3 subunit of the RNA-binding protein CHLAMY1 that is required for correct period and phase of circadian rhythms (Dathe et al., 2012).

\section{Alternative Polyadenylation and Poly(A) Tail Length}

Processing at the mRNA $3^{\prime}$ end comprises pre-mRNA cleavage at the poly $(\mathrm{A})$ site followed by the addition of tracts of adenosines (Xing and Li, 2011). This poly(A) tail influences both mRNA stability and translation. A dedicated group of RNA-binding proteins, the poly(A) binding proteins, bind to the poly(A) tail and additionally interact with the translation initiation factor eIF4G that in turn interacts with the Cap binding protein eIF4E, thus bending the mRNA into a circle. This enables translational control by the poly(A) tail.

New insights into polyadenylation in Arabidopsis came from implementation of direct RNA sequencing, a single molecule technique where native mRNA is used as the template (Sherstnev et al., 2012). This allowed the determination of the site of RNA cleavage and polyadenylation without errors cause by aberrant reverse transcription or PCR amplification during library generation and unveiled a widespread heterogeneity in $3^{\prime}$ ends through alternative polyadenylation (Sherstnev et al., 2012). Such variation in the length of the $3^{\prime}$ UTRs can have functional significance for the resulting transcript isoforms, e.g., due to the presence of different regulatory motifs or miRNA binding sites in $3^{\prime}$ UTRs of different length. The functional consequences of the usage of the alternative polyadenylation sites for core clock genes and genes of clock output remain to be resolved.

In the cytoplasm, poly(A) tail shortening from the $3^{\prime}$ end is catalyzed by deadenylases. This variation in poly(A) tail length can affect mRNA stability. A connection of variation in poly(A) tail length with circadian rhythms has not been addressed in plants.

In mammals, daily fluctuations in poly(A) tail size have initially been observed for the mRNA encoding the neuroactive peptide vasopressin that is synthesized within the suprachiasmatic nuclei and displays rhythmic concentration changes in the cerebrospinal fluid (Robinson et al., 1988). More recently, $2.5 \%$ of transcripts in mouse liver turned out to undergo circadian oscillations in poly(A) tail length in a genome-wide poly(A)denylome analysis using microarrays (Kojima et al., 2012). Interestingly, this variation in poly(A) tail length rather than variation in mRNA steady-state abundance correlated with rhythms in protein abundance, suggesting that the rhythmic variation in the length of the poly(A) tail leads to rhythmic translation.

One of the deadenylases in mammals, Nocturnin, is rhythmically expressed (Wang et al., 2001). Mice deficient for Nocturnin have defects in lipid homeostasis and response to glucose, suggesting that Nocturnin mediates post-transcriptional regulation of metabolic events by the circadian clock.

\section{Translational Control}

Changes in translation efficiency allow a rapid adjustment in the proteome without prior regulation of transcription or RNA processing. Regulation at the level of translation initiation is a topic intensely studied in plants (Roy and von Arnim, 2013). In particular, upstream ORF (uORFs) located $5^{\prime}$ to a reading frame can alter the usage of its start codons. When such uORFs are longer than 25 codons they inhibit translation of the downstream ORF (Nyiko et al., 2009; Roy et al., 2010). About a third of all Arabidopsis genes harbor uORFs but few of them have been functionally studied (Kim et al., 2007a). Alternative splicing of introns in the $5^{\prime}$ UTR can affect the inventory of uORFs. Moreover, miRNAs can affect translation of their target mRNAs (Brodersen et al., 2008; Li et al., 2013).

Several studies in Arabidopsis indicate that protein levels often do not follow rhythmic mRNA levels (Piques et al., 2009; Baerenfaller et al., 2012). In rice seedlings, a number of proteins display oscillations at the protein level that do not correlate with mRNA rhythms (Hwang et al., 2011). On the one hand, 
such observations point to rhythms in translation. On the other hand, cycling of proteins made from rhythmic mRNAs can also be blunted through long half-lives. In tomato, in vivo labeling with $35 \mathrm{~S}$ methionine uncovered circadian oscillations of the translation rate of the photosystem II light harvesting complex polypeptide that closely correlate with the transcript oscillations (Riesselmann and Piechulla, 1992). In contrast, no oscillation was detected at the protein level, perhaps due to the low turnover of this membrane protein.

In Arabidopsis, translation of the core clock gene $L H Y$ has been shown to be influenced by light (Kim et al., 2003). Thus, when LHY transcript levels fall after the dawn peak, light promotes LHY translation. This simultaneous translational induction and transcriptional repression has been suggested to sharpen the LHY protein peak.

Clearly, a more widespread inventory of changes in translation would provide insights into clock-control over translation. Comparing the pool of mRNAs associated with polysomes to the mRNAs not associated with polysomes serves as an indication for active translation. Such a global translatome profiling across the circadian cycle would allow conclusions about changes in the translation status of each transcript in the course of the day (Missra and von Arnim, 2014).

In mammals, dedicated RNA-binding proteins have been identified that control translation of clock genes. The mLARK protein binds to the $3^{\prime}$ UTR of Per 1 and boosts PER1 protein levels, most likely through stimulation of translation (Kojima et al., 2007). Additionally, hnRNPQ rhythmically binds to the Per1 $5^{\prime}$ UTR to stimulate its translation in a time-of-day dependent manner (Lee et al., 2012).

Notably, as many as $50 \%$ of the proteins that cycle in liver are translated from constitutively expressed mRNAs (Reddy et al., 2006). More recently, it has been observed that the clock exerts also a widespread control of the translation apparatus through coordinated transcription of translation initiation factors, ribosomal proteins, and rRNAs (Jouffe et al., 2013). Additionally, distinct signaling pathways impinging on translation initiation factors are rhythmically activated.

In C. reinhardtii, the RNA-binding protein CHLAMY1 regulates translation of output genes. CHLAMY1 binds, in a circadian manner, to transcripts with UG repeats in their $3^{\prime}$ UTR (Zhao et al., 2004). Among these transcripts is NITRITE REDUCTASE (Waltenberger et al., 2001). Consistent with a role for CHLAMY1 as a translational repressor, the activity of NITRITE REDUCTASE in reciprocal to the levels of CHLAMY1 $\mathrm{C} 1$ and 3 subunits.

\section{Non-Coding RNAs}

\section{microRNAs}

Plant miRNAs regulate a wide range of mRNAs predominantly by mRNA cleavage and subsequent degradation but also via inhibition of translation (Figure 1; Rogers and Chen, 2013). In Arabidopsis, a suite of miRNAs were interrogated for rhythmic expression. miR171, miR398, miR168, and miR167 oscillate diurnally but are not under clock-control (Sire et al., 2009). In contrast, the precursors of miR157A, miR158A, miR160B, and miR167D are clock-controlled (Hazen et al., 2009). Whether these daily fluctuations in expression have functional consequences for their targets has not been addressed. Notably, clockregulated RNA-binding protein AtGRP7 impacts processing of several miRNA precursors (Köster et al., 2014b).

In mammals, rhythmic miRNA expression has been widely observed. Several clock genes are targets of miRNAs, and miRNAs have been implicated in the regulation of period length and light resetting of the clock (Nagel et al., 2009). Recently, miR122 was shown to control the expression of the deadenylase nocturnin, another post-transcriptional regulator in the circadian system (Kojima et al., 2010).

\section{Natural Antisense Transcripts}

Arabidopsis contains a large number of convergently overlapping gene pairs that can give rise to natural antisense transcripts (NATs) which might act as regulators of the sense gene (Zubko et al., 2011). Using tiling arrays, rhythmic NATs have been detected for $7 \%$ of the protein coding genes (Hazen et al., 2009). Among these are the oscillator genes LHY, CCA1, TOC1, PRR3, PRR5, PRR7, and PRR9. The functional significance for the oscillator mechanism has not been addressed.

A prime example of antisense RNA regulation in circadian timekeeping is the $N$. crassa frq locus that gives rise to a long non-coding antisense RNA qrf oscillating in antiphase to frq (Kramer et al., 2003). Light-dependent qrf expression is involved in resetting of the clock (Xue et al., 2014). Moreover, frq transcription and qrf transcription are mutually inhibitory, resulting in the antiphasic frq and qrf oscillations. Antisense Per1 transcripts that cycle in antiphase to Per1 have been detected in mouse liver and in silkmoth, suggesting that such pairs of rhythmic antisense RNAs may also play a role in circadian clocks (Sauman and Reppert, 1996; Koike et al., 2012; Menet et al., 2012).

As the number of identified ncRNAs including ncRNAs and siRNAs is increasing, it is conceivable that more ncRNAs will be found to fulfill a role in regulating circadian gene expression.

\section{The Epitranscriptome}

Modification of cellular components by methylation is mostly known for DNA and proteins. Methylation generally depends on the availability of $S$-adenosylmethionine (SAM) that donates the methyl group and the concentration of $S$-adenosylhomocysteine (SAH), a by-product that is a competitive inhibitor of the methylation. The drug 3-deazaadenosine inhibits SAH hydrolysis and thus indirectly inhibits methylation though accumulation of the competitive inhibitor (Chiang, 1998).

The role of histone methylation in clock gene transcription has been established in Arabidopsis (Malapeira et al., 2012; Song and Noh, 2012). The role of non-histone protein methylation in the clock is obvious from the pervasive effect of the prmt5 mutant on the pace of Arabidopsis clock (Hong et al., 2010; Sanchez et al., 2010). 
In contrast to DNA and protein methylation, the physiological role of mRNA modification by methylation of nucleobases is less well understood. Nevertheless, the importance of RNA methylation including methylation of adenine $\left(\mathrm{m}^{6} \mathrm{~A}\right)$ has recently been recognized in plants (Bodi et al., 2012). Impaired $\mathrm{m}^{6} \mathrm{~A}$ methylation affects embryonic development and leads to aberrant growth phenotypes in adult plants. Within transcripts, $\mathrm{m}^{6} \mathrm{~A}$ was found predominantly about 150 nucleotides upstream of the polyadenylation site.

RNA methylation has recently been shown to affect the mammalian clock (Fustin et al., 2013). Treatment of human cells with 3-deazaadenosin led to global changes in gene expression. The gene ontology category "rhythmic processes" ranked fourth among significantly affected processes, suggesting an exquisite sensitivity of the circadian clock to imbalanced methylation. Among the upregulated genes were RNA processing factors including RNA $\mathrm{m}^{7} \mathrm{G}$ cap methylases, m6A demethylases, RNA methylases, and splicing factors. RNA immunoprecipitation using an antibody against $\mathrm{m}^{6} \mathrm{~A}$ then unveiled the presence of $\mathrm{m} 6 \mathrm{~A}$ in many clock gene transcripts. Inhibition of m6A RNA methylation by knockdown of the methyltransferase Mettl3 led to a long period of Per2 driven luciferase activity and locomoter activity. The processing of clock genes including Per2 was delayed which may slow down the speed of the clock.

\section{Conclusion}

Ample evidence has accumulated for discordances between rhythms in promoter activity and rhythms in mRNA levels on the one hand and mRNA and protein rhythms on the other hand, respectively. In particular, the importance of correct alternative pre-mRNA splicing in the Arabidopsis clock has been recognized either through aberrant clock function in splicing factor mutants or the appearance of specific alternative splice isoforms of clock genes. In the future, the recent establishment of STABLE ISOTOPE LABELING by amino acids in cell culture (SILAC) for Arabidopsis seedlings will allow quantitative proteomics and identification of predicted polypeptides corresponding to alternative splice isoforms (Lewandowska et al., 2013). A next logical step is to prove the relevance of alternative splice isoforms by testing their association with polysomes and through complementation of mutants with forced isoform expression. Furthermore, the development of robust RNA immunoprecipitation protocols provides an entré to identify direct targets of candidate splicing factors (Terzi and Simpson, 2009; Köster et al., 2014a).

Although alternative splicing undoubtedly is the layer of posttranscriptional regulation currently understood in most detail in Arabidopsis, it would be premature to assume that it is the most important one. Other RNA processing steps clearly contribute to shaping the circadian transcriptome (Figure 6). This is evident

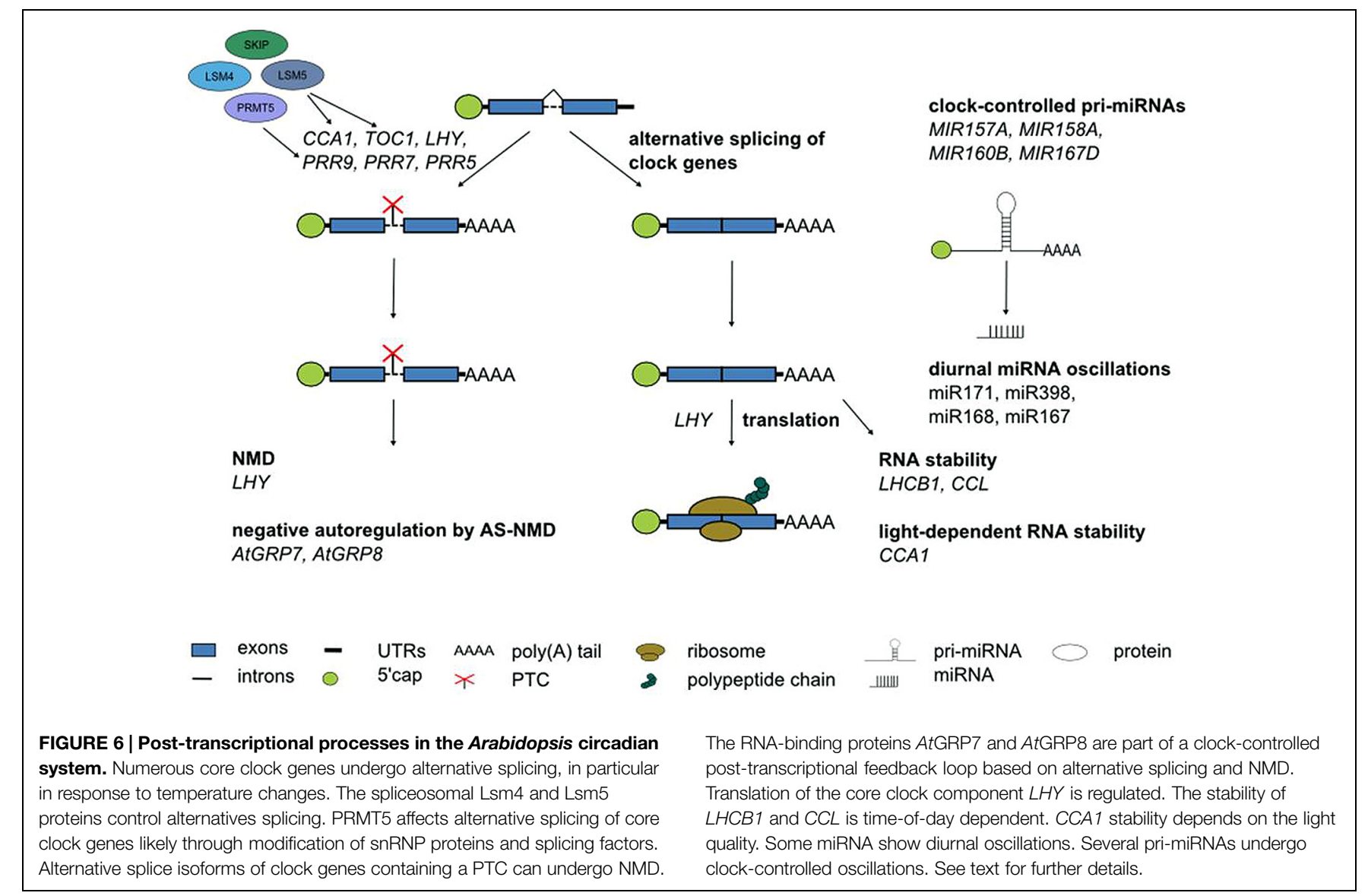


from the anecdotal reports on regulated stability of a few circadian genes, oscillations of a handful of miRNAs or translational regulation of clock genes summarized here. In particular, in the light of fundamental differences in the mechanism of pri-miRNA processing and in target mRNA regulation by miRNAs between animals and plants it will be interesting to see the impact of miRNAs on rhythmic gene expression programs. Novel developments in high throughput techniques combined with more powerful bioinformatics pipelines will help to further shift the focus from individual gene expression patterns to genome-wide

\section{References}

Akhtar, R. A., Reddy, A. B., Maywood, E. S., Clayton, J. D., King, V. M., Smith, A. G., et al. (2002). Circardian cycling of the mouse liver transcriptome, as revealed by cDNA microarray, is driven by the suprachiasmatic nucleus. Curr. Biol. 12, 540-550. doi: 10.1016/S0960-9822(02)00759-5

Alabadi, D., Oyama, T., Yanovsky, M. J., Harmon, F. G., Mas, P., and Kay, S. A. (2001). Reciprocal regulation between TOC1 and LHY/CCA1 within the Arabidopsis circadian clock. Science 293, 880-883. doi: 10.1126/science. 1061320

Arciga-Reyes, L., Wootton, L., Kieffer, M., and Davies, B. (2006). UPF1 is required for nonsense-mediated mRNA decay (NMD) and RNAi in Arabidopsis. Plant J. 47, 480-489. doi: 10.1111/j.1365-313X.2006.02802.x

Baerenfaller, K., Massonnet, C., Walsh, S., Baginsky, S., Buhlmann, P., Hennig, L., et al. (2012). Systems-based analysis of Arabidopsis leaf growth reveals adaptation to water deficit. Mol. Syst. Biol. 8:606. doi: 10.1038/msb.2012.39

Barak, S., Tobin, E. M., Green, R. M., Andronis, C., and Sugano, S. (2000). All in good time: the Arabidopsis circadian clock. Trends Plant Sci. 5, 517-522. doi: 10.1016/S1360-1385(00)01785-4

Barta, A., Kalyna, M., and Reddy, A. S. (2010). Implementing a rational and consistent nomenclature for serine/arginine-rich protein splicing factors (SR Proteins) in plants. Plant Cell 22, 2926-2929. doi: 10.1105/tpc.110.078352

Bell-Pedersen, D., Cassone, V. M., Earnest, D. J., Golden, S. S., Hardin, P. E., Thomas, T. L., et al. (2005). Circadian rhythms from multiple oscillators: lessons from diverse organisms. Nat. Rev. Genet. 6, 544-556. doi: 10.1038/nrg1633

Bodi, Z., Zhong, S., Mehra, S., Song, J., Li, H., Graham, N., et al. (2012). Adenosine methylation in Arabidopsis mRNA is associated with the 3' end and reduced levels cause developmental defects. Front. Plant Sci. 3:48. doi: 10.3389/fpls.2012.00048

Brodersen, P., Sakvarelidze-Achard, L., Bruun-Rasmussen, M., Dunoyer, P., Yamamoto, Y. Y., Sieburth, L., et al. (2008). Widespread translational inhibition by plant miRNAs and siRNAs. Science 320, 1185-1190. doi: 10.1126/science. 1159151

Carvalho, R., Feijao, C., and Duque, P. (2012). On the physiological significance of alternative splicing events in higher plants. Protoplasma 250, 639-650. doi: 10.1007/s00709-012-0448-9

Cech, T. R., and Steitz, J. A. (2014). The noncoding RNA revolution-trashing old rules to forge new ones. Cell 157, 77-94. doi: 10.1016/j.cell.2014

Chiang, P. K. (1998). Biological effects of inhibitors of $S$-adenosylhomocysteine hydrolase. Pharmacol. Ther. 77, 115-134. doi: 10.1016/S0163-7258(97) 00089-2

Covington, M. F., Maloof, J. N., Straume, M., Kay, S. A., and Harmer, S. L. (2008). Global transcriptome analysis reveals circadian regulation of key pathways in plant growth and development. Genome Biol. 9:R130. doi: 10.1186/gb-2008-98-r130

Crosthwaite, S. K. (2004). Circadian clocks and natural antisense RNA. FEBS Lett. 567, 49-54. doi: 10.1016/j.febslet.2004.04.073

Cui, Z., Xu, Q., and Wang, X. (2014). Regulation of the circadian clock through pre-mRNA splicing in Arabidopsis. J. Exp. Bot. 65, 1973-1980. doi: 10.1093/jxb/eru085

Darnell, J. E. (2013). Reflections on the history of pre-mRNA processing and highlights of current knowledge: a unified picture. RNA 19, 443-460. doi: $10.1261 /$ rna.038596.113 impact of these regulatory events. This will advance our knowledge on the importance of other RNA processing steps for the circadian system also in plants, as it has been the case in animals.

\section{Acknowledgments}

$\mathrm{CN}$ is supported by the German National Academic Foundation. The work in our laboratory is supported by the DFG (STA653 and priority program 1530).

Dathe, H., Prager, K., and Mittag, M. (2012). Novel interaction of two clockrelevant RNA-binding proteins $\mathrm{C} 3$ and $\mathrm{XRN} 1$ in Chlamydomonas reinhardtii. FEBS Lett. 586, 3969-3973. doi: 10.1016/j.febslet.2012.09.046

de Montaigu, A., Toth, R., and Coupland, G. (2010). Plant development goes like clockwork. Trends Genet. 26, 296-306. doi: 10.1016/j.tig.2010.04.003

Deng, X., Gu, L., Liu, C., Lu, T., Lu, F., Lu, Z., et al. (2010). Arginine methylation mediated by the Arabidopsis homolog of PRMT5 is essential for proper pre-mRNA splicing. Proc. Natl. Acad. Sci. U.S.A. 107, 19114-19119. doi: 10.1073/pnas.1009669107

Dibner, C., Schibler, U., and Albrecht, U. (2010). The mammalian circadian timing system: organization and coordination of central and peripheral clocks. Annu. Rev. Physiol. 72, 517-549. doi: 10.1146/annurev-physiol-021909-135821

Dixon, L. E., Knox, K., Kozma-Bognar, L., Southern, M. M., Pokhilko, A., and Millar, A. J. (2011). Temporal repression of core circadian genes is mediated through EARLY FLOWERING 3 in Arabidopsis. Curr. Biol. 25, 120-125. doi: 10.1016/j.cub.2010.12.013

Eriksson, M. E., and Millar, A. J. (2003). The circadian Clock. A plant's best friend in a spinning world. Plant Physiol. 132, 732-738. doi: 10.1104/pp.103.022343

Fankhauser, C., and Staiger, D. (2002). Photoreceptors in Arabidopsis thaliana: light perception, signal transduction and entrainment of the endogenous clock. Planta 216, 1-16. doi: 10.1007/s00425-002-0831-4

Filichkin, S. A., Cumbie, J. S., Dharmawadhana, J. P., Jaiswal, P., Chang, J. H., Palusa, S. G., et al. (2015). Environmental stresses modulate abundance and timing of alternatively spliced circadian transcripts in Arabidopsis. Mol. Plant. doi: $10.1093 / \mathrm{mp} / \mathrm{ssu} 130$ [Epub ahead of print].

Filichkin, S., and Mockler, T. (2012). Unproductive alternative splicing and nonsense mRNAs: a widespread phenomenon among plant circadian clock genes. Biol. Direct. 7:20. doi: 10.1186/1745-6150-7-20

Filichkin, S. A., Priest, H. D., Givan, S. A., Shen, R., Bryant, D. W., Fox, S. E., et al. (2010). Genome-wide mapping of alternative splicing in Arabidopsis thaliana. Genome Res. 20, 45-58. doi: 10.1101/gr.093302.109

Fujiwara, S., Wang, L., Han, L., Suh, S. S., Salome, P. A., McClung, C. R., et al. (2008). Post-translational regulation of the Arabidopsis circadian clock through selective proteolysis and phosphorylation of pseudo-response regulator proteins. J. Biol. Chem. 283, 23073-23083. doi: 10.1074/jbc.M803471200

Fustin, J.-M., Doi, M., Yamaguchi, Y., Hida, H., Nishimura, S., Yoshida, M., et al. (2013). RNA-Methylation-dependent RNA processing controls the speed of the circadian clock. Cell 155, 793-806. doi: 10.1016/j.cell.2013.10.026

Gahura, O., Abrhámová, K., Skružný, M., Valentová, A., Munzarová, V., Folk, P., et al. (2009). Prp45 affects Prp22 partition in spliceosomal complexes and splicing efficiency of non-consensus substrates. J. Cell. Biochem. 106, 139-151. doi: $10.1002 /$ jcb. 21989

Gendron, J. M., Pruneda-Paz, J. L., Doherty, C. J., Gross, A. M., Kang, S. E., and Kay, S. A. (2012). Arabidopsis circadian clock protein, TOC1, is a DNAbinding transcription factor. Proc. Natl. Acad. Sci. U.S.A. 109, 3167-3172. doi: 10.1073/pnas.1200355109

Gloggnitzer, J., Akimcheva, S., Srinivasan, A., Kusenda, B., Riehs, N., Stampfl, H., et al. (2014). Nonsense-mediated mRNA decay modulates immune receptor levels to regulate plant antibacterial defense. Cell Host Microbe 16, 376-390. doi: 10.1016/j.chom.2014.08.010

Golisz, A., Sikorski, P. J., Kruszka, K., and Kufel, J. (2013). Arabidopsis thaliana LSM proteins function in mRNA splicing and degradation. Nucleic Acids Res. 41, 6232-6249. doi: 10.1093/nar/gkt296 
Guo, J., Cheng, P., Yuan, H., and Liu, Y. (2009). The exosome regulates circadian gene expression in a posttranscriptional negative feedback loop. Cell 138, 1236-1246. doi: 10.1016/j.cell.2009.06.043

Gutierrez, R. A., Ewing, R. M., Cherry, J. M., and Green, P. J. (2002). Identification of unstable transcripts in Arabidopsis by cDNA microarray analysis: rapid decay is associated with a group of touch- and specific clock-controlled genes. Proc. Natl. Acad. Sci. U.S.A. 99, 11513-11518. doi: 10.1073/pnas.152204099

Hackmann, C., Korneli, C., Kutyniok, M., Köster, T., Wiedenlübbert, M., Müller, C., et al. (2014). Salicylic acid-dependent and -independent impact of an RNA-binding protein on plant immunity. Plant Cell Environ. 37, 696-706. doi: $10.1111 /$ pce. 12188

Harmer, S. L. (2009). The circadian system in higher plants. Annu. Rev. Plant Biol. 60, 357-377. doi: 10.1146/annurev.arplant.043008.092054

Harms, E., Kivimae, S., Young, M. W., and Saez, L. (2004). Posttranscriptional and posttranslational regulation of clock genes. J. Biol. Rhythms 19, 361-373. doi: 10.1177/0748730404268111

Hazen, S. P., Naef, F., Quisel, T., Gendron, J. M., Chen, H., Ecker, J. R., et al. (2009). Exploring the transcriptional landscape of plant circadian rhythms using genome tiling arrays. Genome Biol. 10:R17. doi: 10.1186/gb-200910-2-r17

Helfer, A., Nusinow, D. A., Chow, B. Y., Gehrke, A. R., Bulyk, M. L., and Kay, S. A. (2011). LUX ARRHYTHMO encodes a nighttime repressor of circadian gene expression in the Arabidopsis core clock. Curr. Biol. 21, 126-133. doi: 10.1016/j.cub.2010.12.021

Henriques, R., and Mas, P. (2013). Chromatin remodeling and alternative splicing: pre- and post-transcriptional regulation of the Arabidopsis circadian clock. Semi. Cell Dev. Biol. 24, 399-406. doi: 10.1016/j.semcdb.2013. 02.009

Herrero, E., and Davis, S. J. (2012). Time for a nuclear meeting: protein trafficking and chromatin dynamics intersect in the plant circadian system. Mol. Plant 5, 554-565. doi: 10.1093/mp/sss010

Herrero, E., Kolmos, E., Bujdoso, N., Yuan, Y., Wang, M., Berns, M. C., et al. (2012). EARLY FLOWERING4 recruitment of EARLY FLOWERING3 in the nucleus sustains the Arabidopsis circadian clock. Plant Cell 24, 428-443. doi: 10.1105/tpc.111.093807

Hong, S., Song, H. R., Lutz, K., Kerstetter, R. A., Michael, T. P., and McClung, C. R. (2010). Type II protein arginine methyltransferase 5 (PRMT5) is required for circadian period determination in Arabidopsis thaliana. Proc. Natl. Acad. Sci. U.S.A. 107, 21211-21216. doi: 10.1073/pnas.1011987107

Houseley, J., and Tollervey, D. (2009). The many pathways of RNA degradation. Cell 136, 763-776. doi: 10.1016/j.cell.2009.01.019

Hsu, P. Y., and Harmer, S. L. (2014). Wheels within wheels: the plant circadian system. Trends Plant Sci. 19, 240-249. doi: 10.1016/j.tplants.2013.11.007

Huang, W., Perez-Garcia, P., Pokhilko, A., Millar, A. J., Antoshechkin, I., Riechmann, J. L., et al. (2012). Mapping the core of the Arabidopsis circadian clock defines the network structure of the oscillator. Science 336, 75-79. doi: $10.1126 /$ science. 1219075

Hurley, J. M., Dasgupta, A., Emerson, J. M., Zhou, X., Ringelberg, C. S., Knabe, N., et al. (2014). Analysis of clock-regulated genes in Neurospora reveals widespread posttranscriptional control of metabolic potential. Proc. Natl. Acad. Sci. U.S.A. 111, 16995-17002. doi: 10.1073/pnas.1418963111

Hwang, H. J., Cho, M.-H., Hahn, B.-S., Lim, H., Kwon, Y.-K., Hahn, T.-R., et al. (2011). Proteomic identification of rhythmic proteins in rice seedlings. Biochim. Biophys. Acta 1840, 470-479. doi: 10.1016/j.bbapap.2011.01.010

Isken, O., and Maquat, L. E. (2008). The multiple lives of NMD factors: balancing roles in gene and genome regulation. Nat. Rev. Genet. 9, 699-712. doi: $10.1038 / \operatorname{nrg} 2402$

James, A. B., Syed, N. H., Bordage, S., Marshall, J., Nimmo, G. A., Jenkins, G. I., et al. (2012). Alternative splicing mediates responses of the Arabidopsis circadian clock to temperature changes. Plant Cell 24, 961-981. doi: 10.1105/tpc.111.093948

Jones, M. A., Williams, B. A., Mcnicol, J., Simpson, C. G., Brown, J. W. S., and Harmer, S. L. (2012). Mutation of Arabidopsis SPLICEOSOMAL TIMEKEEPER LOCUS1 causes circadian clock defects. Plant Cell 24, 4907-4916. doi: 10.1105/tpc.112.104828

Jouffe, C., Cretenet, G., Symul, L., Martin, E., Atger, F., Naef, F., et al. (2013). The circadian clock coordinates ribosome biogenesis. PLoS Biol. 11:e1001455. doi: 10.1371/journal.pbio. 1001455
Keene, J. D. (2007). Biological clocks and the coordination theory of RNA operons and regulons. Cold. Spring Harb. Symp. Quant. Biol. 72, 157-165. doi: $10.1101 /$ sqb. 2007.72 .013

Kim, B.-H., Cai, X., Vaughn, J., and von Arnim, A. (2007a). On the functions of the h subunit of eukaryotic initiation factor 3 in late stages of translation initiation. Genome Biol. 8:R60. doi: 10.1186/gb-2007-8-4-r60

Kim, J. S., Park, S. J., Kwak, K. J., Kim, Y. O., Kim, J. Y., Song, J., et al. (2007b). Cold shock domain proteins and glycine-rich RNA-binding proteins from Arabidopsis thaliana can promote the cold adaptation process in Escherichia coli. Nucleic Acids Res. 35, 506-516. doi: 10.1093/nar/gkl1076

Kim, E.-D., and Sung, S. (2012). Long noncoding RNA: unveiling hidden layer of gene regulatory networks. Trends Plant Sci. 17, 16-21. doi: 10.1016/j.tplants.2011.10.00

Kim, J. S., Jung, H. J., Lee, H. J., Kim, K. A., Goh, C. H., Woo, Y., et al. (2008). Glycine-rich RNA-binding protein7 affects abiotic stress responses by regulating stomata opening and closing in Arabidopsis thaliana. Plant J. 55, 455-466. doi: 10.1111/j.1365-313X.2008.03518.x

Kim, J.-Y., Song, H.-R., Taylor, B. L., and Carré, I. A. (2003). Light-regulated translation mediates gated induction of the Arabidopsis clock protein LHY. EMBO J. 22, 935-944. doi: 10.1093/emboj/cdg075

Kim, S.-H., Lee, K.-H., Kim, D.-Y., Kwak, E., Kim, S., and Kim, K.-T. (2015). Rhythmic control of mRNA stability modulates circadian amplitude of mouse period3 mRNA. J. Neurochem. 132, 642-656. doi: 10.1111/jnc.13027

Koike, N., Yoo, S.-H., Huang, H.-C., Kumar, V., Lee, C., Kim, T.-K., et al. (2012). Transcriptional architecture and chromatin landscape of the core circadian clock in mammals. Science 338, 349-354. doi: 10.1126/science.1226339

Kojima, S., Gatfield, D., Esau, C. C., and Green, C. B. (2010). MicroRNA-122 modulates the rhythmic expression profile of the circadian deadenylase Nocturnin in mouse liver. PLoS ONE 5:e11264. doi: 10.1371/journal.pone.0011264

Kojima, S., and Green, C. B. (2014). Circadian genomics reveal a role for post-transcriptional regulation in mammals. Biochemistry 54, 124-133. doi: $10.1021 /$ bi500707c

Kojima, S., Matsumoto, K., Hirose, M., Shimada, M., Nagano, M., Shigeyoshi, Y., et al. (2007). LARK activates posttranscriptional expression of an essential mammalian clock protein, PERIOD1. Proc. Natl. Acad. Sci. U.S.A. 104, 18591864. doi: 10.1073/pnas.0607567104

Kojima, S., Sher-Chen, E. L., and Green, C. B. (2012). Circadian control of mRNA polyadenylation dynamics regulates rhythmic protein expression. Genes Dev. 26, 2724-2736. doi: 10.1101/gad.208306.112

Kojima, S., Shingle, D. L., and Green, C. B. (2011). Post-transcriptional control of circadian rhythms. J. Cell Sci. 124, 311-320. doi: 10.1242/jcs.065771

Koncz, C., Dejong, F., Villacorta, N., Szakonyi, D., and Koncz, Z. (2012). The spliceosome-activating complex: molecular mechanisms underlying the function of a pleiotropic regulator. Front. Plant Sci. 3:9. doi: 10.3389/fpls.2012.00009

Kornblihtt, A. R., Schor, I. E., Allo, M., Dujardin, G., Petrillo, E., and Munoz, M. J. (2013). Alternative splicing: a pivotal step between eukaryotic transcription and translation. Nat. Rev. Mol. Cell Biol. 14, 153-165. doi: 10.1038/ nrm3525

Köster, T., Haas, M., and Staiger, D. (2014a). The RIPper Case: identification of RNA-binding protein targets by RNA immunoprecipitation. Methods Mol. Biol. 1158, 107-121. doi: 10.1007/978-1-4939-0700-7_7

Köster, T., Meyer, K., Weinholdt, C., Smith, L. M., Lummer, M., Speth, C., et al. (2014b). Regulation of pri-miRNA processing by the hnRNP-like protein AtGRP7 in Arabidopsis. Nucleic Acids Res. 42, 9925-9936. doi: 10.1093/nar/gku716

Kramer, C., Loros, J. J., Dunlap, J. C., and Crosthwaite, S. K. (2003). Role for antisense RNA in regulating circadian clock function in Neurospora crassa. Nature 421, 948-952. doi: 10.1038/nature01427

Kwak, E., Kim, T. D., and Kim, K. T. (2006). Essential role of 3'-untranslated region-mediated mRNA decay in circadian oscillations of mouse Period3 mRNA. J. Biol. Chem. 281, 19100-19106. doi: 10.1074/jbc.M511927200

Leder, V., Lummer, M., Tegeler, K., Humpert, F., Lewinski, M., Schüttpelz, M., et al. (2014). Mutational definition of binding requirements of an hnRNP-like protein in Arabidopsis using fluorescence correlation spectroscopy. Biochem. Biophys. Res. Commun. 453, 69-74. doi: 10.1016/j.bbrc.2014.09.056

Lee, K.-H., Kim, S.-H., Kim, H.-J., Kim, W., Lee, H.-R., Jung, Y., et al. (2014). AUF1 contributes to Cryptochrome1 mRNA degradation and rhythmic translation. Nucleic Acids Res. 42, 3590-3606. doi: 10.1093/nar/gkt1379 
Lee, K. H., Woo, K. C., Kim, D. Y., Kim, T. D., Shin, J., Park, S. M., et al. (2012). Rhythmic interaction between Period1 mRNA and HnRNP Q leads to circadian time-dependent translation. Mol. Cell. Biol. 32, 717-728. doi: 10.1128/MCB.06177-11

Lewandowska, D., Ten Have, S., Hodge, K., Tillemans, V., Lamond, A. I., and Brown, J. W. S. (2013). Plant SILAC: stable-isotope labelling with amino acids of Arabidopsis seedlings for quantitative proteomics. PLoS ONE 8:e72207. doi: 10.1371/journal.pone.0072207

Li, S., Liu, L., Zhuang, X., Yu, Y., Liu, X., Cui, X., et al. (2013). MicroRNAs inhibit the translation of target mRNAs on the Endoplasmic Reticulum in Arabidopsis. Cell 153, 562-574. doi: 10.1016/j.cell.2013.04.005

Lidder, P., Gutierrez, R. A., Salome, P. A., McClung, C. R., and Green, P. J. (2005) Circadian control of messenger RNA stability. Association with a sequencespecific messenger RNA decay pathway. Plant Physiol. 138, 2374-2385. doi: 10.1104/pp.105.060368

Liu, Y., Heintzen, C., Loros, J., and Dunlap, J. C. (1999). Regulation of clock genes. Cell Mol. Life Sci. 55, 1195-1205. doi: 10.1007/s000180050366

Löhr, B., Streitner, C., Steffen, A., Lange, T., and Staiger, D. (2014). A glycine-rich RNA-binding protein affects gibberellin biosynthesis in Arabidopsis. Mol. Biol. Rep. 41, 439-445. doi: 10.1007/s11033-013-2878-7

Lück, S., Thurley, K., Thaben, P. F., and Westernmark, P. O. (2014). Rhythmic degradation explains and unifies circadian transcriptome and proteome data. Cell Rep. 9, 741-751. doi: 10.1016/j.celrep.2014.09.021

Malapeira, J., Khaitova, L. C., and Mas, P. (2012). Ordered changes in histone modifications at the core of the Arabidopsis circadian clock. Proc. Natl. Acad. Sci. U.S.A. 109, 21540-21545. doi: 10.1073/pnas.1217022110

Maris, C., Dominguez, C., and Allain, F. H. (2005). The RNA recognition motif, a plastic RNA-binding platform to regulate post-transcriptional gene expression. FEBS J. 272, 2118-2131. doi: 10.1111/j.1742-4658.2005.04653.x

Marquez, Y., Brown, J. W. S., Simpson, C. G., Barta, A., and Kalyna, M. (2012). Transcriptome survey reveals increased complexity of the alternative splicing landscape in Arabidopsis. Genome Res. 22, 1184-1195. doi: 10.1101/gr.134106.111

Mas, P., Kim, W. Y., Somers, D. E., and Kay, S. A. (2003). Targeted degradation of TOC1 by ZTL modulates circadian function in Arabidopsis thaliana. Nature 426, 567-570. doi: 10.1038/nature02163

Matsuo, T., Okamoto, K., Onai, K., Niwa, Y., Shimogawara, K., and Ishiura, M. (2008). A systematic forward genetic analysis identified components of the Chlamydomonas circadian system. Genes Dev. 22, 918-930. doi: $10.1101 /$ gad. 1650408

Matsushika, A., Imamura, A., Yamashino, T., and Mizuno, T. (2002). Aberrant expression of the light-inducible and circadian-regulated APRR9 gene belonging to the circadian-associated APRR1/TOC1 quintet results in the phenotype of early flowering in Arabidopsis thaliana. Plant Cell Physiol. 43, 833-843. doi: $10.1093 / \mathrm{pcp} / \mathrm{pcf} 118$

McClung, C. R. (2006). Plant circadian rhythms. Plant Cell 18, 792-803. doi: $10.1105 /$ tpc. 106.040980

McClung, C. R. (2011). The genetics of plant clocks. Adv. Genet. 74, 105-139. doi: 10.1016/B978-0-12-387690-4.00004-0

McGlincy, N. J., and Smith, C. W. (2008). Alternative splicing resulting in nonsense-mediated mRNA decay: what is the meaning of nonsense? Trends Biochem. Sci. 33, 385-393. doi: 10.1016/j.tibs.2008.06.001

Mehra, A., Baker, C. L., Loros, J. J., and Dunlap, J. C. (2009). Post-translational modifications in circadian rhythms. Trends Biochem. Sci. 34, 483-490. doi: 10.1016/j.tibs.2009.06.006

Menet, J. S., Rodriguez, J., Abruzzi, K. C., and Rosbash, M. (2012). Nascent-Seq reveals novel features of mouse circadian transcriptional regulation. eLife Sci. 1:e00011. doi: 10.7554/eLife.00011

Michael, T. P., and McClung, C. R. (2002). Phase-specific circadian clock regulatory elements in Arabidopsis. Plant Physiol. 130, 627-638. doi: 10.1104/pp.004929

Michael, T. P., and McClung, C. R. (2003). Enhancer trapping reveals widespread circadian clock transcriptional control in arabidopsis. Plant Physiol. 132, 629639. doi: $10.1104 /$ pp.021006

Millar, A. J. (2004). Input signals to the plant circadian clock. J. Exp. Bot. 55, 277-283. doi: 10.1093/jxb/erh034

Millar, A. J., and Kay, S. (1991). Circadian control of cab gene transcription and mRNA accumulation in Arabidopsis. Plant Cell 3, 541-550. doi: 10.1105/tpc.3.5.541
Missra, A., and von Arnim, A. (2014). "Analysis of mRNA translation states in Arabidopsis over the diurnal cycle by polysome microarray," in Plant Circadian Networks, ed. D. Staiger (New York, NY: Springer), 157-174. doi: 10.1007/9781-4939-0700-7_10

Nagel, D. H., and Kay, S. A. (2012). Complexity in the wiring and regulation of plant circadian networks. Curr. Biol. 22, R648-R657. doi: 10.1016/j.cub.2012.07.025

Nagel, R., Clijsters, L., and Agami, R. (2009). The miRNA-192/194 cluster regulates the Period gene family and the circadian clock. FEBS J. 276, 5447-5455. doi: 10.1111/j.1742-4658.2009.07229.x

Newman, T. C., Ohme-Takagi, M., Taylor, C. B., and Green, P. J. (1993). DST sequences, highly conserved among plant SAUR genes, target reporter transcripts for rapid decay in tobacco. Plant Cell 5, 701-714. doi: 10.1105/ tpc.5.6.701

Nicaise, V., Joe, A., Jeong, B., Korneli, C., Boutrot, F., Wested, I., et al. (2013). Pseudomonas HopU1 affects interaction of plant immune receptor mRNAs to the RNA-binding protein GRP7. EMBO J. 32, 701-712. doi: 10.1038/emboj.2013.15

Nicholson, P., and Mühlemann, O. (2010). Cutting the nonsense: the degradation of PTC-containing mRNAs. Biochem. Soc. Trans. 38, 1615-1620. doi: 10.1042/BST0381615

Nilsen, T. W., and Graveley, B. R. (2010). Expansion of the eukaryotic proteome by alternative splicing. Nature 463, 457-463. doi: 10.1038/nature08909

Nyiko, T., Sonkoly, B., Merai, Z., Benkovics, A. H., and Silhavy, D. (2009). Plant upstream ORFs can trigger nonsense-mediated mRNA decay in a sizedependent manner. Plant Mol. Biol. 71, 367-378. doi: 10.1007/s11103-0099528-4

Partch, C. L., Green, C. B., and Takahashi, J. S. (2013). Molecular architecture of the mammalian circadian clock. Trends Cell Biol. 24, 90-99. doi: 10.1016/j.tcb.2013.07.002

Perea-Resa, C., Hernandez-Verdeja, T., Lopez-Cobollo, R., Castellano, M. D. M., and Salinas, J. (2012). LSM proteins provide accurate splicing and decay of selected transcripts to ensure normal Arabidopsis development. Plant Cell 24, 4930-4947. doi: 10.1105/tpc.112.103697

Perez-Santángelo, S., Mancini, E., Francey, L. J., Schlaen, R. G., Chernomoretz, A., Hogenesch, J. B., et al. (2014). Role for LSM genes in the regulation of circadian rhythms. Proc. Natl. Acad. Sci. U.S.A. 111, 15166-15171. doi: 10.1073/pnas.1409791111

Perez-Santángelo, S., Schlaen, R. G., and Yanovsky, M. J. (2013). Genomic analysis reveals novel connections between alternative splicing and circadian regulatory networks. Brief. Funct. Genomics 12, 13-24. doi: 10.1093/bfgp/els052

Pilgrim, M. L., Caspar, T., Quail, P. H., and McClung, C. R. (1993). Circadian and light-regulated expression of nitrate reductase in Arabidopsis. Plant Mol. Biol. 23, 349-364. doi: 10.1007/BF00029010

Piques, M., Schulze, W. X., Hohne, M., Usadel, B., Gibon, Y., Rohwer, J., et al. (2009). Ribosome and transcript copy numbers, polysome occupancy and enzyme dynamics in Arabidopsis. Mol. Syst. Biol. 5:314. doi: 10.1038/msb.2009.68

Preußner, M., Wilhelmi, I., Schultz, A.-S., Finkernagel, F., Michel, M., Möröy, T., et al. (2014). Rhythmic U2af26 alternative splicing controls PERIOD1 stability and the circadian clock in mice. Mol. Cell 54, 651-662. doi: 10.1016/j.molcel.2014.04.015

Proudfoot, N. J. (2011). Ending the message: poly(A) signals then and now. Genes Dev. 25, 1770-1782. doi: 10.1101/gad.17268411

Reddy, A. B., Karp, N. A., Maywood, E. S., Sage, E. A., Deery, M., O’neill, J. S., et al. (2006). Circadian orchestration of the hepatic proteome. Curr. Biol. 16, 1107-1115. doi: 10.1016/j.cub.2006.04.026

Reddy, A. S. (2004). Plant serine/arginine-rich proteins and their role in pre-mRNA splicing. Trends Plant Sci. 9, 541-547. doi: 10.1016/j.tplants.2004.09.007

Reddy, A. S. N., Marquez, Y., Kalyna, M., and Barta, A. (2013). Complexity of the alternative splicing landscape in plants. Plant Cell 25, 3657-3683. doi: $10.1105 /$ tpc. 113.117523

Reddy, A. S. N., Rogers, M. F., Richardson, D. N., Hamilton, M., and Ben-Hur, A (2012). Deciphering the plant splicing code: experimental and computational approaches for predicting alternative splicing and splicing regulatory elements. Front. Plant Sci. 3:18. doi: 10.3389/fpls.2012.00018

Riesselmann, S., and Piechulla, B. (1992). Diurnal and circadian lightharvesting complex and quinone B-binding protein synthesis in leaves 
of tomato (Lycopersicon esculentum). Plant Physiol. 100, 1840-1845. doi: 10.1104/pp.100.4.1840

Robinson, B. G., Frim, D. M., Schwartz, W. J., and Majzoub, J. A. (1988). Vasopressin mRNA in the suprachiasmatic nuclei: daily regulation of polyadenylate tail length. Science 241, 342-344. doi: 10.1126/science.3388044

Roden, L. C., and Carré, I. A. (2001). The molecular genetics of circadian rhythms in Arabidopsis. Semin. Cell Dev. Biol. 12, 305-315. doi: 10.1006/scdb.2001.0258

Rogers, K., and Chen, X. (2013). Biogenesis, Turnover, and mode of action of plant microRNAs. Plant Cell 25, 2383-2399. doi: 10.1105/tpc.113.113159

Roy, B., Vaughn, J. N., Kim, B.-H., Zhou, F., Gilchrist, M. A., and von Arnim, A. G. (2010). The h subunit of eIF3 promotes reinitiation competence during translation of mRNAs harboring upstream open reading frames. RNA 16, 748-761. doi: 10.1261/rna.2056010

Roy, B., and von Arnim, A. G. (2013). Translational regulation of cytoplasmic mRNAs. Arabidopsis Book 11:e0165. doi: 10.1199/tab.0165

Rudolf, F., Wehrle, F., and Staiger, D. (2004). Slave to the rhythm. Biochemistry 26, $11-13$.

Sanchez, S. E., Petrillo, E., Beckwith, E. J., Zhang, X., Rugnone, M. L., Hernando, C. E., et al. (2010). A methyl transferase links the circadian clock to the regulation of alternative splicing. Nature 468, 112-116. doi: 10.1038/nature09470

Sanchez, S. E., Petrillo, E., Kornblihtt, A. R., and Yanovsky, M. J. (2011). Alternative splicing at the right time. RNA Biol. 8, 954-959. doi: 10.4161/rna.8.6.17336

Sauman, I., and Reppert, S. M. (1996). Circadian clock neurons in the silkmoth Antheraea pernyi: novel mechanisms of period protein regulation. Neuron 17, 889-900. doi: 10.1016/S0896-6273(00)80220-2

Schmal, C., Reimann, P., and Staiger, D. (2013). A circadian clock-regulated toggle switch explains AtGRP7 and AtGRP8 oscillations in Arabidopsis thaliana. PLoS Comput. Biol. 9:e1002986. doi: 10.1371/journal.pcbi.1002986

Schmidt, F., Marnef, A., Cheung, M. K., Wilson, I., Hancock, J., Staiger, D., et al. (2010). A proteomic analysis of oligo(dT)-bound mRNP containing oxidative stress-induced Arabidopsis thaliana RNA-binding proteins ATGRP7 and ATGRP8. Mol. Biol. Rep. 37, 839-845. doi: 10.1007/s11033-009-9636-x

Schöning, J. C., and Staiger, D. (2005). At the pulse of time: protein interactions determine the pace of circadian clocks. FEBS Lett. 579, 3246-3252. doi: 10.1016/j.febslet.2005.03.028

Schöning, J. C., Streitner, C., Meyer, I. M., Gao, Y., and Staiger, D. (2008). Reciprocal regulation of glycine-rich RNA-binding proteins via an interlocked feedback loop coupling alternative splicing to nonsense-mediated decay in Arabidopsis. Nucleic Acids Res. 36, 6977-6987. doi: 10.1093/nar/gkn847

Schöning, J. C., Streitner, C., Page, D. R., Hennig, S., Uchida, K., Wolf, E., et al. (2007). Autoregulation of the circadian slave oscillator component AtGRP7 and regulation of its targets is impaired by a single RNA recognition motif point mutation. Plant J. 52, 1119-1130. doi: 10.1111/j.1365-313X.2007.03302.x

Seo, P. J., and Mas, P. (2014). Multiple layers of posttranslational regulation refine circadian clock activity in Arabidopsis. Plant Cell 26, 79-87. doi: 10.1105/tpc.113.119842

Seo, P. J., Park, M.-J., Lim, M.-H., Kim, S.-G., Lee, M., Baldwin, I. T., et al. (2012). A self-regulatory circuit of CIRCADIAN CLOCK-ASSOCIATED1 underlies the circadian clock regulation of temperature responses in Arabidopsis. Plant Cell 24, 2427-2442. doi: 10.1105/tpc.112.098723

Sherstnev, A., Duc, C., Cole, C., Zacharaki, V., Hornyik, C., Ozsolak, F., et al. (2012). Direct sequencing of Arabidopsis thaliana RNA reveals patterns of cleavage and polyadenylation. Nat. Struct. Mol. Biol. 19, 845-852. doi: $10.1038 / \mathrm{nsmb} .2345$

Shikata, H., Hanada, K., Ushijima, T., Nakashima, M., Suzuki, Y., and Matsushita, T. (2014). Phytochrome controls alternative splicing to mediate light responses in Arabidopsis. Proc. Natl. Acad. Sci. U.S.A. 111, 18781-18786. doi: 10.1073/pnas.1407147112

Sire, C., Moreno, A. B., Garcia-Chapa, M., Lopez-Moya, J. J., and San Segundo, B. (2009). Diurnal oscillation in the accumulation of Arabidopsis microRNAs, miR167, miR168, miR171 and miR398. FEBS Lett. 583, 1039-1044. doi: 10.1016/j.febslet.2009.02.024

So, W. V., and Rosbash, M. (1997). Post-transcriptional regulation contributes to Drosophila clock gene mRNA cycling. EMBO J. 16, 7146-7155. doi: 10.1093/emboj/16.23.7146

Song, H.-R., and Noh, Y.-S. (2012). Rhythmic oscillation of histone acetylation and methylation at the Arabidopsis central clock loci. Mol. Cells 34, 279-287. doi: 10.1007/s10059-012-0103-5
Staiger, D. (2001). RNA-binding proteins and circadian rhythms in Arabidopsis thaliana. Philo. Trans. R. Soc. Lond. B Biol. Sci. 356, 1755-1759. doi: 10.1098/rstb.2001.0964

Staiger, D. (2002). Circadian rhythms in Arabidopsis: time for nuclear proteins. Planta 214, 334-344. doi: 10.1007/s004250100662

Staiger, D., and Brown, J. W. S. (2013). Alternative splicing at the intersection of biological timing, development, and stress responses. Plant Cell 25, 3640-3656. doi: $10.1105 /$ tcp. 113.117523

Staiger, D., and Green, R. (2011). RNA-based regulation in the plant circadian clock. Trends Plant Sci. 16, 517-523. doi: 10.1016/j.tplants.2011.06.002

Staiger, D., and Heintzen, C. (1999). The circadian system of Arabidopsis thaliana: forward and reverse genetic approaches. Chronobiol. Int. 16, 1-16. doi: $10.3109 / 07420529908998708$

Staiger, D., and Köster, T. (2011). Spotlight on post-transcriptional control in the circadian system. Cell Mol. Life. Sci. 68, 71-83. doi: 10.1007/s00018-0100513-5

Staiger, D., Shin, J., Johansson, M., and Davis, S. J. (2013). The circadian clock goes genomic. Genome Biol. 14:208. doi: 10.1186/gb-2013-14-6-208

Streitner, C., Hennig, L., Korneli, C., and Staiger, D. (2010). Global transcript profiling of transgenic plants constitutively overexpressing the RNA-binding protein AtGRP7. BMC Plant Biol. 10:221. doi: 10.1186/1471-2229-10-221

Streitner, C., Köster, T., Simpson, C. G., Shaw, P., Danisman, S., Brown, J. W. S., et al. (2012). An hnRNP-like RNA-binding protein affects alternative splicing by in vivo interaction with target transcripts in Arabidopsis thaliana. Nucleic Acids Res. 40, 11240-11255. doi: 10.1093/nar/gks873

Syed, N. H., Kalyna, M., Marquez, Y., Barta, A., and Brown, J. W. S. (2012). Alternative splicing in plants - coming of age. Trends Plant Sci. 17, 616-623. doi: 10.1016/j.tplants.2012.06.001

Tannukit, S., Crabb, T. L., Hertel, K. J., Wen, X., Jans, D. A., and Paine, M. L. (2009). Identification of a novel nuclear localization signal and speckletargeting sequence of tuftelin-interacting protein 11, a splicing factor involved in spliceosome disassembly. Biochem. Biophys. Res. Commun. 390, 1044-1050. doi: 10.1016/j.bbrc.2009.10.111

Terzi, L. C., and Simpson, G. G. (2009). Arabidopsis RNA immunoprecipitation. Plant J. 59, 163-168. doi: 10.1111/j.1365-313X.2009.03859.x

Tharun, S. (2009). Roles of eukaryotic Lsm proteins in the regulation of mRNA function. Int. Rev. Cell. Mol. Biol. 272, 149-189. doi: 10.1016/S19376448(08)01604-3

Wachter, A., Rühl, C., and Stauffer, E. (2012). The role of polypyrimidine tractbinding proteins and other hnRNP proteins in plant splicing regulation. Front. Plant Sci. 3:81. doi: 10.3389/fpls.2012.00081

Waltenberger, H., Schneid, C., Grosch, J. O., Bareiss, A., and Mittag, M. (2001). Identification of target mRNAs for the clock-controlled RNA-binding protein chlamy 1 from Chlamydomonas reinhardtii. Mol. Genet. Genomics 265, 180-188. doi: $10.1007 /$ s004380000406

Wang, D., Liang, X., Chen, X., and Guo, J. (2013). Ribonucleoprotein complexes that control circadian clocks. Int. J. Mol. Sci. 14, 9018-9036. doi 10.3390/ijms 14059018

Wang, L., Fujiwara, S., and Somers, D. E. (2010). PRR5 regulates phosphorylation, nuclear import and subnuclear localization of TOC1 in the Arabidopsis circadian clock. $E M B O$ J. 29, 1903-1915. doi: 10.1038/emboj.2010.76

Wang, X., Wu, F., Xie, Q., Wang, H., Wang, Y., Yue, Y., et al. (2012). SKIP Is a component of the spliceosome linking alternative splicing and the circadian clock in Arabidopsis. Plant Cell 24, 3278-3295. doi: 10.1105/tpc.112.100081

Wang, Y., Osterbur, D. L., Megaw, P. L., Tosini, G., Fukuhara, C., Green, C. B., et al. (2001). Rhythmic expression of Nocturnin mRNA in multiple tissues of the mouse. BMC Dev. Biol. 1:9. doi: 10.1186/1471-213X-1-9

Woo, K. C., Ha, D. C., Lee, K. H., Kim, D. Y., Kim, T. D., and Kim, K. T. (2010). Circadian amplitude of cryptochrome 1 is modulated by mRNA stability regulation via cytoplasmic hnRNP D oscillation. Mol. Cell. Biol. 30, 197-205. doi: 10.1128/MCB.01154-09

Woo, K. C., Kim, T. D., Lee, K. H., Kim, D. Y., Kim, W., Lee, K. Y., et al. (2009). Mouse period 2 mRNA circadian oscillation is modulated by PTBmediated rhythmic mRNA degradation. Nucleic Acids Res. 37, 26-37. doi: 10.1093/nar/gkn893

Wuarin, J., Falvey, E., Lavery, D., Talbot, D., Schmidt, E., Ossipow, V., et al. (1992). The role of the transcriptional activator protein DBP in circadian liver gene expression. J. Cell Sci. 16, 123-127. doi: 10.1242/jcs.1992.Supplement_16.15 
Xing, D., and Li, Q. Q. (2011). Alternative polyadenylation and gene expression regulation in plants. Wiley Interdiscip. Rev. RNA 2, 445-458. doi: 10.1002/wrna.59

Xue, Z., Ye, Q., Anson, S. R., Yang, J., Xiao, G., Kowbel, D., et al. (2014). Transcriptional interference by antisense RNA is required for circadian clock function. Nature 514, 650-653. doi: 10.1038/ nature 13671

Yakir, E., Hilman, D., Hassidim, M., and Green, R. M. (2007). CCA1 Transcript stability and the entrainment of the circadian clock in Arabidopsis. Plant Physiol. 145, 925-932. doi: 10.1104/pp.107.103812

Yanovsky, M. J., and Kay, S. A. (2001). Signaling networks in the plant circadian system. Curr. Opin. Plant Biol. 4, 429-435. doi: 10.1016/S1369-5266(00) 00196-5

Yerushalmi, S., Yakir, E., and Green, R. M. (2011). Circadian clocks and adaptation in Arabidopsis. Mol. Ecol. 20, 1155-1165. doi: 10.1111/j.1365294X.2010.04962.x

Young, M. W., and Kay, S. A. (2001). Time zones: a comparative genetics of circadian clocks. Nat. Rev. Genet. 2, 702-715. doi: 10.1038/35088576

Zhang, L., Weng, W., and Guo, J. (2011). Posttranscriptional mechanisms in controlling eukaryotic circadian rhythms. FEBS Lett. 585, 1400-1405. doi: 10.1016/j.febslet.2011.03.018

Zhang, N., Kallis, R. P., Ewy, R. G., and Portis, A. R. (2002). Light modulation of Rubisco in Arabidopsis requires a capacity for redox regulation of the larger
Rubisco activase isoform. Proc. Natl. Acad. Sci. U.S.A. 99, 3330-3334. doi: 10.1073/pnas.042529999

Zhao, B., Schneid, C., Iliev, D., Schmidt, E. M., Wagner, V., Wollnik, F., et al. (2004). The circadian RNA-binding protein CHLAMY 1 represents a novel type heteromer of RNA recognition motif and lysine homology domain-containing subunits. Eukaryot. Cell 3, 815-825. doi: 10.1128/EC.3.3.815-825.2004

Zhong, H. H., Resnick, A. S., Straume, M., and McClung, C. R. (1997). Effects of synergistic signaling by phytochrome A and cryptochrome 1 on circadian clockregulated catalase expression. Plant Cell 9, 947-955. doi: 10.1105/tpc.9.6.947

Zubko, E., Kunova, A., and Meyer, P. (2011). Sense and antisense transcripts of convergent gene pairs in Arabidopsis thaliana can share a common polyadenylation region. PLOS ONE 6:e16769. doi: 10.1371/journal.pone.0016769

Conflict of Interest Statement: The authors declare that the research was conducted in the absence of any commercial or financial relationships that could be construed as a potential conflict of interest.

Copyright (c) 2015 Nolte and Staiger. This is an open-access article distributed under the terms of the Creative Commons Attribution License (CC BY). The use, distribution or reproduction in other forums is permitted, provided the original author(s) or licensor are credited and that the original publication in this journal is cited, in accordance with accepted academic practice. No use, distribution or reproduction is permitted which does not comply with these terms. 